\title{
The synergistic interaction between the calcineurin B subunit and IFN- $\gamma$ enhances macrophage antitumor activity
}

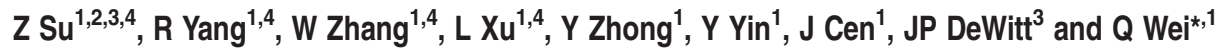

Macrophages are involved in tumor growth and progression. They infiltrate into tumors and cause inflammation, which creates a microenvironment favoring tumor growth and metastasis. However, certain stimuli may induce macrophages to act as tumor terminators. Here we report that the calcineurin B subunit (CnB) synergizes with IFN- $\gamma$ to make macrophages highly cytotoxic to cancer cells. Furthermore, $\mathrm{CnB}$ and IFN- $\gamma$ act synergistically to polarize mouse tumor-associated macrophages, as well as human monocyte-derived macrophages to an M1-like phenotype. This synergy is mediated by the crosstalk between CnB-engaged integrin $\alpha$ M-p38 MAPK signaling and IFN- $\gamma$-initiated p38/PKC- $\delta / J a k 2$ signaling. Interestingly, the signal transducer and activator of transcription 1 (STAT1) is a key factor that orchestrates the synergy of $\mathrm{CnB}$ and IFN- $\gamma$, and the phosphorylation status at Ser727 and Tyr701 of STAT1 is directly regulated by $\mathrm{CnB}$ and IFN- $\gamma$.

Cell Death and Disease (2015) 6, e1740; doi:10.1038/cddis.2015.92; published online 7 May 2015

Calcineurin ( $\mathrm{Cn}$ ) is the only known $\mathrm{Ca}^{2+} /$ calmodulin-dependent serine/threonine protein phosphatase; it is a heterodimer composed of a $61-\mathrm{kDa}$ catalytic subunit $(\mathrm{CnA})$ and a $19-\mathrm{kDa}$ regulatory subunit $(\mathrm{CnB}))^{1,2}$ This enzyme, expressed in various cell types, can modulate T-cell activation, ${ }^{3}$ neuronal excitability, ${ }^{4,5}$ apoptosis, ${ }^{6,7}$ cardiac hypertrophy, ${ }^{8,9}$ and inflammation. $^{10}$

Although $\mathrm{CnB}$ can regulate the phosphatase activity of the $\mathrm{CnA},{ }^{11,12}$ this subunit also has additional non-regulatory roles. Cytosolic $\mathrm{CnB}$ can interact with tubulin, heat shock protein $60,{ }^{13}$ procaspase- $3,{ }^{14}$ and $\mathrm{PSMA} 7{ }^{15}$ and may therefore function in modulating apoptosis, as well as the ubiquitin/proteasome pathway. $\mathrm{CnB}$ also induces dendritic cell maturation and activation and enhances antigen presentation. In fact, this function of $\mathrm{CnB}$ has been utilized as the basis for a novel adjuvant for both cancer vaccine ${ }^{16}$ and the Engerix-B HBV vaccine. ${ }^{17}$ Additionally, we have reported that $\mathrm{CnB}$ can also interact with integrin $a \mathrm{M}$ and induce TNF-related apoptosisinducing ligand (TRAIL) expression in macrophages. ${ }^{18,19}$ Furthermore, intraperitoneal injection of $\mathrm{CnB}$ protein can prolong the survival of mice bearing $\mathrm{H} 22$ ascitic tumors and inhibit the growth of $\mathrm{S} 180$ sarcomas in mice. ${ }^{20}$

IFN- $\gamma$, the sole type II interferon, is a cytokine that is critical for both innate and adaptive immunity to viral and bacterial infections and for tumor surveillance. ${ }^{21-24}$ It is mainly produced by CD4+ $\mathrm{T}$ helper cells, CD8+ cytotoxic T lymphocytes, and NK cells. ${ }^{21,25,26}$ It is also produced by $B$ cells, NKT cells, antigen-presenting cells such as monocytes/ macrophages, and dendritic cells. ${ }^{27,28}$ The cellular response to interferons is mainly mediated through signal transducer and activator of transcription 1 (STAT1). ${ }^{29}$ STAT1 contains two major phosphorylation sites: Tyr701 and Ser727; IFN- $\gamma$ induced STAT1 Tyr701 phosphorylation is thought to be mediated by Janus kinase 2 (Jak2), while Ser727 phosphorylation is thought to be mediated by p38 mitogen-activated protein kinase (MAPK) or protein kinase C- $\delta$ (PKC- $\delta$ ). ${ }^{30-32}$ Phosphorylation at Tyr701 is thought to be important for the formation of a homodimer (i.e., STAT1:STAT1) and heterotrimers (i.e., STAT1:STAT1:interferon regulatory factor (IRF)-9 and STAT1:STAT2:IRF-9), which translocate to the nucleus, bind to IFN- $\gamma$ response elements, and initiate transcription of a series of IFN- $\gamma$-regulated genes such as ICAM-1, CXC-chemokine ligand (CXCL) 9,10, IRF-1, 2, TRAIL, inducible nitric oxide synthase (iNOS), and IFN- $\beta$. In contrast to the role of phosphorylation at Tyr701, phosphorylation of STAT1 at Ser727 is required for maximal transcription of target genes, ${ }^{30,33,34}$ most likely by promoting interaction with proteins such as MCM-5 and BRCA1. ${ }^{35,36}$ Cellular stress (e.g., UV irradiation), cytokines (e.g., IL-2, IL-12), and TLR agonists (e.g., LPS) do not induce STAT1 Tyr701 phosphorylation but stimulate STAT1 Ser727 phosphorylation. ${ }^{31,37-39}$ Thus phosphorylation of STAT on Ser727 functions as a key target linking extracellular stimuli with IFN- $\gamma$ signaling, which in turn leads to maximal activation of innate immune cells. ${ }^{31,38,39}$

Tumors have a complex cellular program that supports both their growth and expansion. In the micro-ecosystem, innate immune cells, especially macrophages cause inflammation and serve a critical role in tumor progression by supporting

\footnotetext{
${ }^{1}$ Department of Biochemistry and Molecular Biology, Beijing Normal University, Gene Engineering and Biotechnology Beijing Key Laboratory, Beijing, PR China; ${ }^{2}$ Department of Biochemistry and Molecular Biology, Medical School, Southeast University, Nanjing, Jiangsu, PR China and ${ }^{3}$ Department of Cell Biology, Harvard Medical School, Boston, MA 02115, USA

*Corresponding author: Q Wei, Department of Biochemistry and Molecular Biology, Beijing Normal University, Beijing 10087, PR China; Gene engineering and Biotechnology Beijing Key Laboratory, Beijing 10087, PR China. Tel/Fax: +86 10 58807365; E-mail: weiq @ bnu.edu.cn

${ }^{4}$ These authors contributed equally to this work and should be considered as co-first authors.

Abbreviations: CnB, calcineurin B subunit; STAT1, signal transducer and activator of transcription 1; Cn, calcineurin; TRAIL, TNF-related apoptosis-inducing ligand; Jak2, Janus kinase 2; MAPK, mitogen-activated protein kinase; PKC- $\delta$, protein kinase C- $\delta$; IRF, interferon regulatory factor; CXCL, CXC-chemokine ligand; iNOS, inducible nitric oxide synthase; ARG1, arginase-1; TAM, tumor-associated macrophage; PBMC, peripheral blood mononuclear cell

Received 24.11.14; revised 14.2.15; accepted 23.2.15; Edited by H-U Simon
} 
angiogenesis, promoting tumor cell invasion, migration, and intravasation, as well as suppressing antitumor immune responses. ${ }^{40,41}$ Usually, macrophages are divided into two categories based on their secretory profile and function: M1like subtype and M2-like subtype. M1-like branches are classically activated macrophages in response to IFN- $\gamma$ with Toll-like receptor engagement and are characterized by their cytotoxity and by high expression of IL-12, CD86, CXCL9, CXCL10, IL-23, IL-6, and TRAIL. ${ }^{42,43}$ In contrast, M2-like branches are alternatively activated macrophages in response to IL-4 and IL-13 and are characterized by high expression of CD206, arginase-1 (ARG1), and IL-10. ${ }^{44}$ In general, tumor-associated macrophages (TAMs) exhibit M2like properties and promote tumor progression. However, the precise ratio of $\mathrm{M} 1$ to $\mathrm{M} 2$ macrophages in the tumor and its microenvironment may determine the tumor viability and progression. In nonprogressing or regressing tumors, macrophages are shifted to an M1-like subtype; in malignant tumors, macrophages resemble an M2-like subtype. ${ }^{40}$ Specific microenvironmental signals or immunoregulatory cues may skew the ratio of $\mathrm{M} 1 / \mathrm{M} 2$ macrophages and reverse the role of macrophages as accomplices in tumor progression to aides in tumor termination. ${ }^{40,45,46}$

Our findings showed a synergistic effect of $\mathrm{CnB}$ and IFN- $\gamma$, which resulted in a sudden burst of TRAIL expression in macrophages. We further investigated the synergistic tumorsuppressive effect of $\mathrm{CnB}$ and IFN- $\gamma$ in vitro and in vivo and explored possible mechanisms of both the macrophage transformation and the interferon signaling amplification.

\section{Results}

CnB and IFN- $\gamma$ act synergistically to enhance tumoricidal ability of RAW264.7 macrophages. As previously described, IFN- $\gamma$ induces a robust transcriptional response in RAW264.7 macrophages ${ }^{47}$; this cytokine elicits the transcription upregulation of TRAIL, iNOS, CXCL9, and CXCL10 (Figure 1a). In contrast, $\mathrm{CnB}$ alone has minimal activity in inducing the activation of these genes (Figure 1a). Interestingly, the combination of $\mathrm{CnB}$ with IFN- $\gamma$ elicites a robust synergistic increase in the mRNA levels in both a dose(Figure 1a) and time-dependent manner (Figure 1b). The combination of $\mathrm{CnB}$ with IFN- $\gamma$ also induces a significant synergistic increase in the protein levels (Figures 1c-f). CXCL9, CXCL10, and nitric oxide production are remarkably increased upon the combination treatment with $\mathrm{CnB}$ and IFN$\gamma$, compared with the $\mathrm{CnB}$ or IFN- $\gamma$ treatment alone (Figures 1c-e). CD86 expression on RAW264.7 is also further enhanced in response to the synergistic stimulation, compared with the single-drug treatments (Figure 1f). To understand how CnB can facilitate this synergism, we examined IRF-1 and IRF-9, two key transcription factors that control IFN- $\gamma$ - mediated gene expression, including CXCL10, TRAIL, iNOS, and IFN- $\beta .^{48-51}$ In this study, we found that $\mathrm{CnB}$ and IFN- $\gamma$ had a significant cooperative effect on the induction of these two critical transcription factors. Interestingly, CnB treatment alone did not induce IRF-1 and IRF-9 mRNA expression, but the transcript levels increased in response to IFN- $\gamma$ (Figure 1g). These data suggest that $\mathrm{CnB}$ can modulate IFN- $\gamma$-dependent signaling in macrophages but do not address the impact of this synergy in the context of the immune antitumor response. In order to examine whether combination treatment could enhance the antitumor activity of immune cells, we co-cultured RAW264.7 macrophages with $\mathrm{H} 22$ hepatocarcinoma cells. Although treatment with $\mathrm{CnB}$ or IFN- $\gamma$ alone only partially induced $\mathrm{H} 22$ cell apoptosis (Figure 1h, 30 and 50\%, respectively), cotreatment of CnB with IFN- $\gamma$-activated RAW264.7 macrophages caused almost complete H22 cell apoptosis (Figure 1h, 95\%).

CnB synergizes with IFN- $\gamma$ to polarize the mouse TAMs as well as human monocyte-derived macrophages to an M1like differentiation. To determine whether the synergy between $\mathrm{CnB}$ and IFN- $\gamma$ that mediates their antitumor activity was mediated through the conversion of macrophages from an M2-like phenotype to an M1-like phenotype, we isolated TAMs from B16-F10 melanoma from C57BL/6 mice. Flow cytometry analysis showed that the purity of these TAMs was $>85 \%$ (Figure $2 \mathrm{a}$ ). These cells were treated with $\mathrm{CnB}, \mathrm{IFN}-\gamma$, and $\mathrm{CnB}$ with IFN- $\gamma$. To determine whether $\mathrm{CnB}$ with IFN- $\gamma$ could shift the phenotype of these cells, we examined several markers of the M1 (IL-12, CD86, TRAIL, CXCL9 and CXCL10) and M2 phenotype (CD206). Although CnB with IFN- $\gamma$ strongly enhanced the transcript levels of the M1 phenotypic markers, IL-12, CD86, TRAIL, CXCL9 and CXCL10 (Figures $2 b-f$ ), CnB and IFN- $\gamma$ did not synergize to downregule the M2-associated transcript CD206 (Figure 2g). $\mathrm{CnB}$ with IFN- $\gamma$ also increased the protein levels of $\mathrm{M} 1$ phenotypic markers, such as IL-12 and CXCL9 (Figures 2h-i). These data suggest that $\mathrm{CnB}$ together with IFN- $\gamma$ induce TAMs towards an M1-like phenotype.

The data thus far examine the synergy of $\mathrm{CnB}$ and IFN- $\gamma$ in mouse TAMs but do not address whether this phenomenon exists in human-derived cells. To examine whether $\mathrm{CnB}$ and IFN- $\gamma$ can also shift human monocyte-derived macrophages toward an M1-like phenotype, we examined the levels of IL-12 in these cells. Although $\mathrm{CnB}$ and IFN- $\gamma$ alone induced a mild increase of IL-12 mRNA levels (2.7-fold, CnB; 0.67-fold IFN- $\gamma$; Figure $3 a$ ) the combination of $\mathrm{CnB}$ with IFN- $\gamma$ elicited a marked increase in this M1-associated transcript (107-fold; Figure 3a). Similarly, another M1 differentiation marker, TRAIL was also greatly upregulated in response to combination treatment (Figure 3b). Interestingly, in these human-derived cells, two M2-associated transcripts, CD206 and ARG1 expression, were cooperatively downregulated by $\mathrm{CnB}$ and IFN- $\gamma$ combination treatment (Figures $3 c$ and d). The synergy in the protein levels was not as robust as in the mRNAs levels, but we still can see a significant synergetic increase in the IL-12 and TRAIL production (Figures $3 e$ and $f$ ) and a decrease in the CD206 expression (Figure $3 \mathrm{~g}$ ) on human monocyte-derived macrophages. These data suggest that the combination of $\mathrm{CnB}$ with IFN- $\gamma$ can shift the macrophage profile towards an M1 phenotype in both mouse- and human-derived cells.

CnB strongly induces phosphorylation of STAT1, and combined use of $\mathrm{CnB}$ and IFN- $\gamma$ markedly enhances phosphorylation of STAT1 at Ser727 but not at Tyr701. To determine the molecular basis for the synergism of $\mathrm{CnB}$ and IFN- $\gamma$, we focused on STAT1, a key factor involved in the 


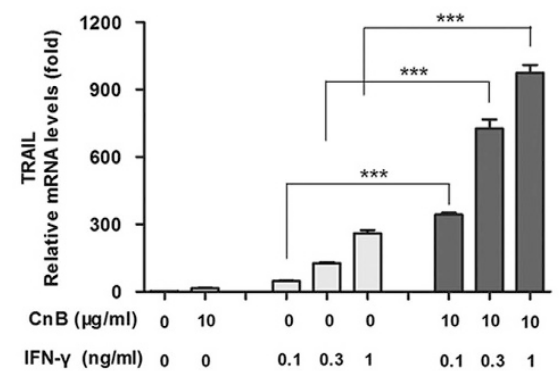

CXCL9

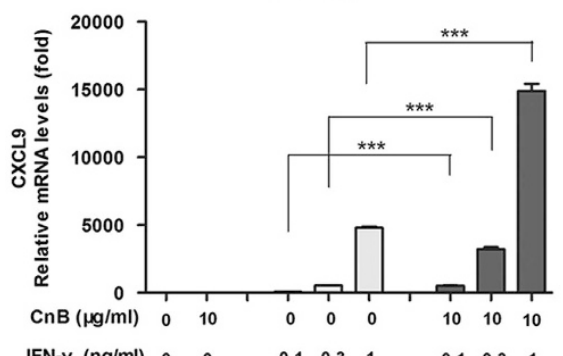

CXCL10

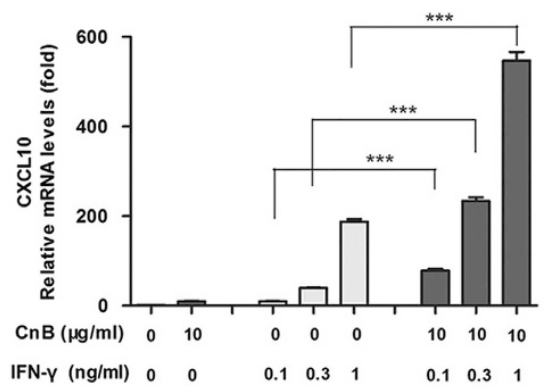

iNOS

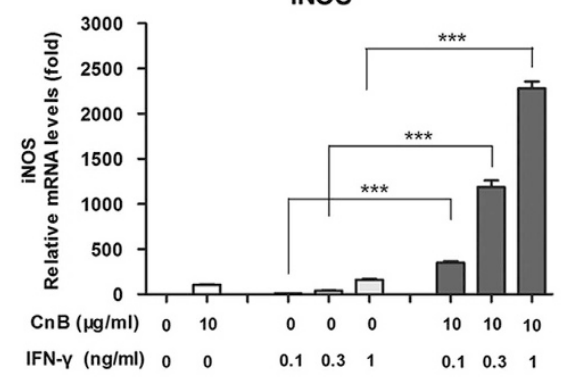

b

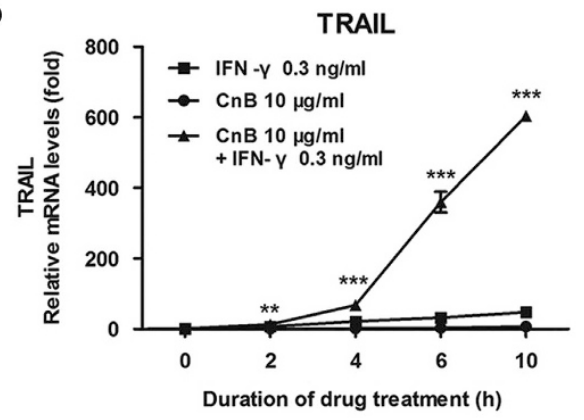

CXCL9

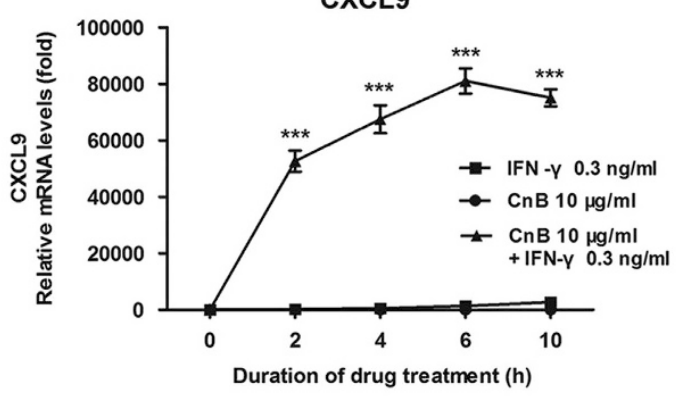

CXCL10

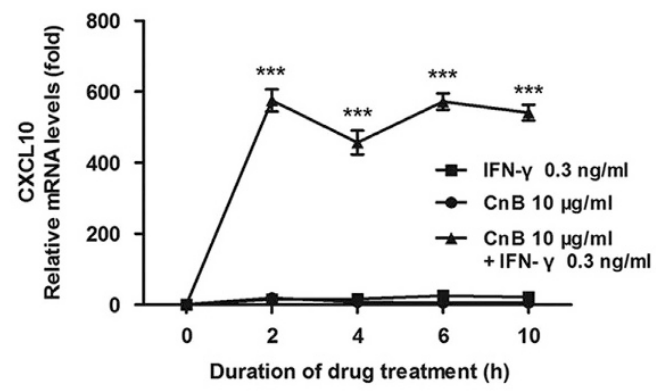

iNOS



Figure $1 \mathrm{CnB}$ and IFN- $\gamma$ act synergistically in enhancing tumoricidal ability of RAW264.7 macrophages. (a) Quantitative PCR (qPCR) assay of the synergistic effect of CnB and IFN- $\gamma$ in inducing TRAIL, iNOS, CXCL9, and CXCL10 transcripts (dose course). Cells were incubated with $\mathrm{CnB}(10 \mu \mathrm{g} / \mathrm{ml}), \mathrm{IFN}-\gamma(0.1-1 \mathrm{ng} / \mathrm{ml})$, or $\mathrm{CnB}(10 \mu \mathrm{g} / \mathrm{ml})+\mathrm{IFN}-\gamma$ $(0.1-1 \mathrm{ng} / \mathrm{ml})$ for $10 \mathrm{~h}$. Results were normalized to $\beta$-actin expression and are presented as fold increases over the medium-only control. (b) qPCR assay of the synergistic effect of $\mathrm{CnB}$ and IFN- $\gamma$ (time course). Cells were preincubated with $\mathrm{CnB}(10 \mu \mathrm{g} / \mathrm{ml})$ for $45 \mathrm{~min}$; then the culture medium was removed and replaced with fresh medium with or without IFN- $\gamma(0.3 \mathrm{ng} / \mathrm{ml})$ and cultured for 2-10 h. (c and d) Enzyme-linked immunosorbent assay of the synergistic effect of CnB and IFN- $\gamma$ (time course). c: IL-12; d: CXCL9. (e) The synergistic effect of $\mathrm{CnB}$ and IFN- $\gamma$ in promoting nitric oxide release. (f) Flow cytometry analysis of CD86 expression. Cells were treated with $\mathrm{CnB}(20 \mu \mathrm{g} / \mathrm{ml})$, IFN- $\gamma(3 \mathrm{ng} / \mathrm{ml})$, or $\mathrm{CnB}(20 \mu \mathrm{g} / \mathrm{ml})+\mathrm{IFN}-\gamma(3 \mathrm{ng} / \mathrm{ml})$ for $24 \mathrm{~h}$. P1, percentage of CD86-negative cells; P2, percentage of CD86-positive cells; Green: isotype control; Black: medium control; Blue: CnB; Red: IFN- $\gamma$; Gray: $\mathrm{CnB}+\mathrm{IFN}-\gamma$. (g) qPCR assay of the transcription factors IRF-1 and IRF-9 expression upon drug treatments (0-2h). (h) Synergistic antitumor effect of $\mathrm{CnB}$ and IFN- $\gamma$ in vitro. Drugs-stimulated RAW264.7 cells were co-cultured with $\mathrm{H} 22$ hepatocarcinoma cells for $30 \mathrm{~h}$. $\mathrm{H} 22$ cells in the supernatants were harvested, and apoptosis was analyzed by fluorescein isothiocyanate-Annexin V/propidium iodide staining. The graph to the right of panel (h) is a quantitative analysis of the total apoptosis rate of $\mathrm{H} 22$ cells. The total apoptosis rate was given by the percentage of Annexin V-positive cells. In panels $\mathbf{b}-\mathbf{e}$ and $\mathbf{g}$, the $t$-tests were carried out between $\mathrm{CnB}+\mathrm{IFN}-\gamma$ treatment and IFN- $\gamma$ treatment alone. ${ }^{\star} P<0.05,{ }^{\star \star} P<0.01,{ }^{\star \star \star} P<0.001$ 
C

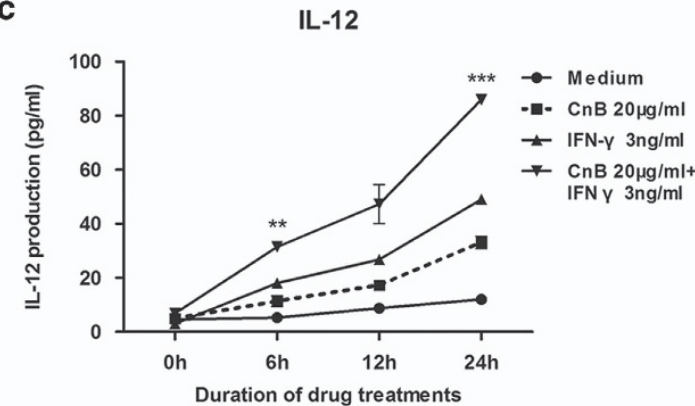

d

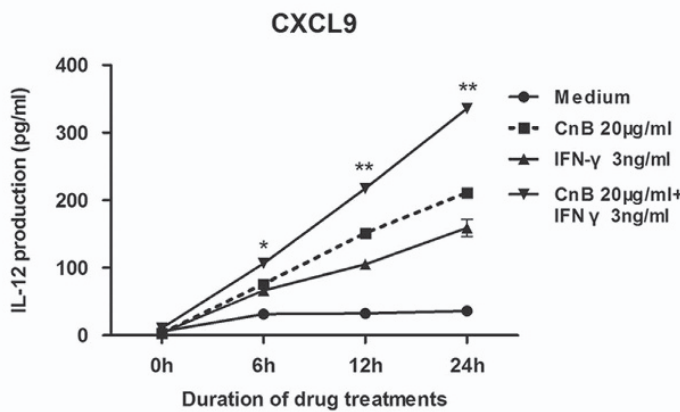

g



e

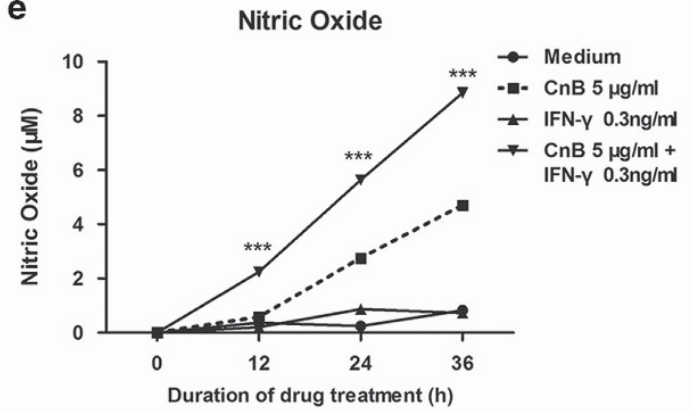

f

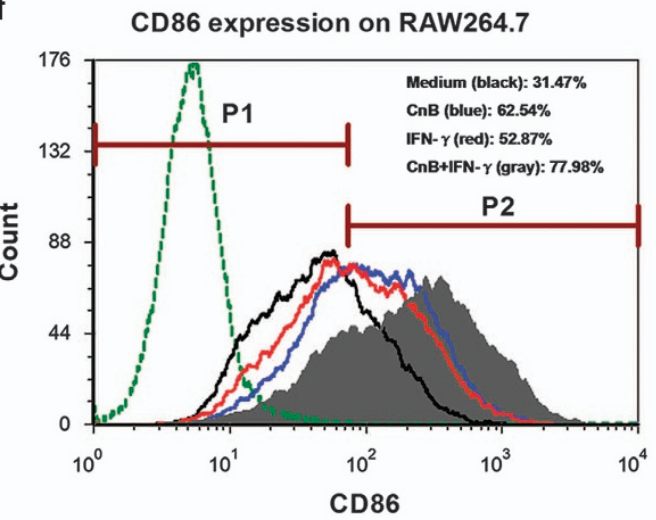

IRF-9

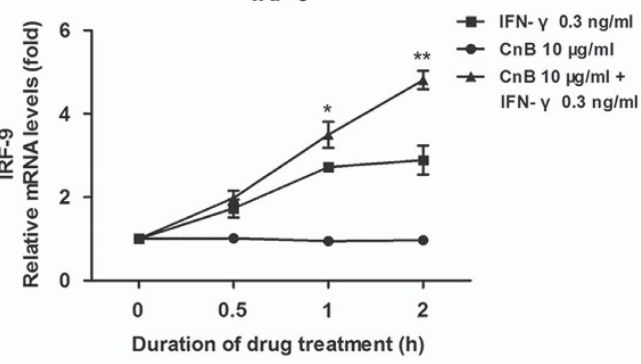

h
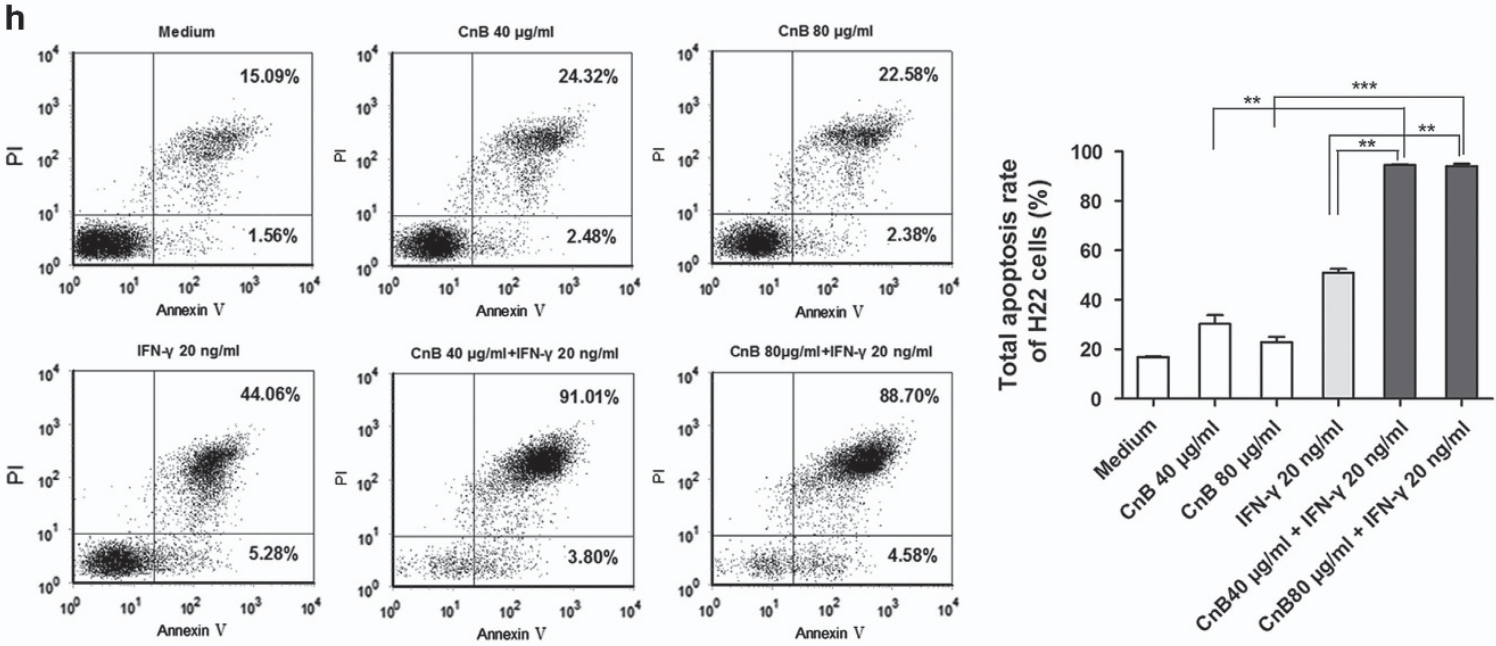

Figure 1 Continued 


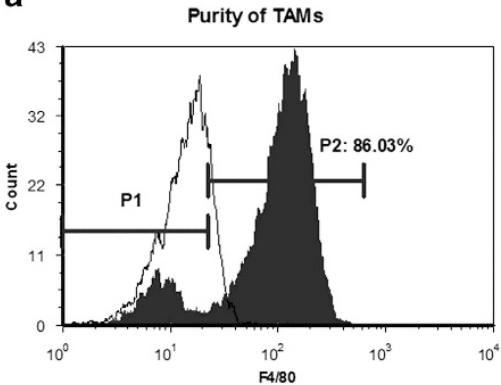

d



g

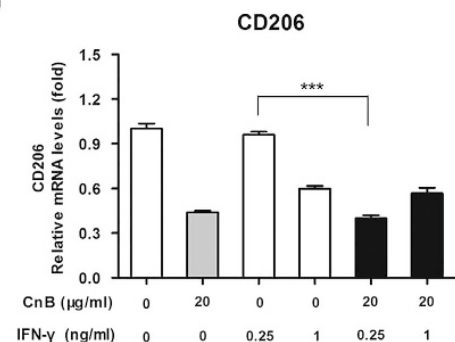

b



e

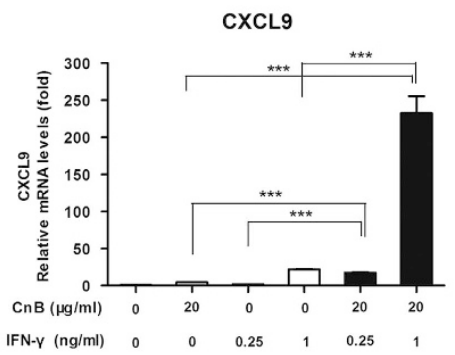

h

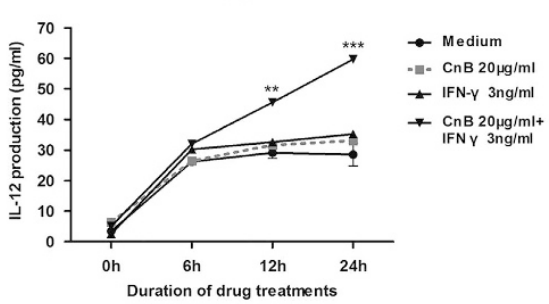

C

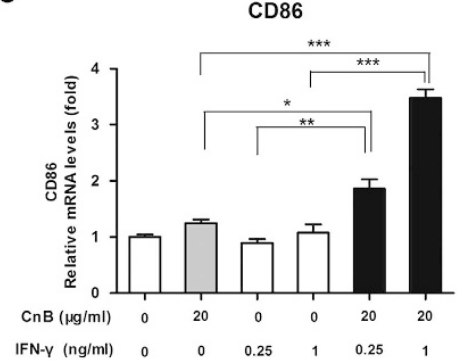

f

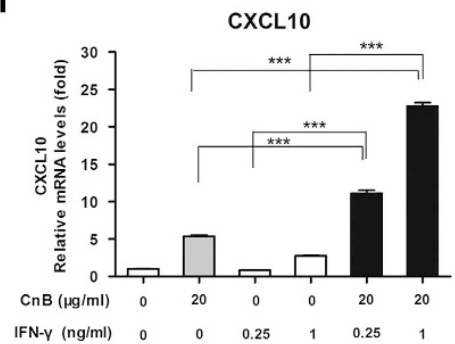

i

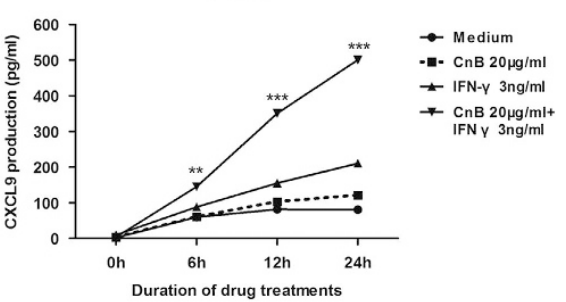

Figure $2 \mathrm{CnB}$ synergizes with IFN- $\gamma$ to polarize TAMs to M1-like phenotype in vitro. (a) Identification of TAMs' purity. P2 represents the percentage of F4/80-positive cells. Filled histogram represents the fluorescence of F4/80 antibody staining, and open histogram represents the fluorescence of isotype antibody staining. (b-g) Quantitative PCR analysis of M1 and M2 markers' expression in drugs-stimulated TAMs. Duration of drug treatments, $10 \mathrm{~h}$. b: lL-12; c: CD86; d: TRAlL; e: CXCL9; f: CXCL10; g: CD206. (h and i) Enzyme-linked immunosorbent assay of IL-12 and CXCL9 production (time course). $\mathbf{h}$ : IL-12; i: CXCL9. In panels $\mathbf{h}$ and $\mathbf{i}$, the $t$-tests were carried out between CnB+IFN- $\gamma$ treatment and IFN- $\gamma$ treatment alone. ${ }^{*} P<0.05,{ }^{\star *} P<0.01,{ }^{* \star *} P<0.001$

interferon signaling pathway, and tested whether $\mathrm{CnB}$ and IFN- $\gamma$ synergized in promoting STAT1 phosphorylation. We examined CnB-induced phosphorylation of STAT1; CnB induced a robust and prolonged phosphorylation of STAT1 at Ser727 that lasted for $5 \mathrm{~h}$ after treatment (Figure $4 \mathrm{a}$ ). Conversely, $\mathrm{CnB}$ induced weak and slow phosphorylation of STAT1 at Tyr701 (Figure 4a). Because CnB was expressed and purified from bacterial cultures, and LPS can also induce phosphorylation of STAT $1,{ }^{52}$ we sought to distinguish the CnBinduced STAT1 phosphorylation from the presumed LPSinduced STAT1 phosphorylation. In the proteinase $\mathrm{K}$ digestion experiment, we found that the proteinase K-digested CnB lost the ability to induce phosphorylation of STAT1 (Figure $4 \mathrm{~b}$ ), thus demonstrating that the CnB-induced STAT1 phosphorylation was not due to LPS contamination. We next studied the cooperative effect in a time-course analysis, showing that $\mathrm{CnB}$ pretreatment for 20 min significantly enhanced IFN- $\gamma$-induced STAT1 phosphorylation at Ser727 but not at Tyr701 (Figure 4c). Similar findings were obtained as a function of dose (Figure 4d). The time- and dosage-dependent results were consistent with the weak nature of the $\mathrm{CnB}$ induction of STAT1 phosphorylation at Tyr701.
CnB-induced STAT1 phosphorylation is dependent on integrin aM-p38 pathway. Previous studies suggest that p38 MAPK is necessary for mediating the phosphorylation of STAT1 on Ser727. ${ }^{31,37,38,39}$ Therefore, we investigated whether CnB activates p38 and whether CnB-induced STAT1 phosphorylation is also mediated by this kinase. CnB elicited a rapid p38 phosphorylation, which increased gradually over 300 min (Figure 5a). CnB-induced Ser727 phosphorylation and Tyr701 phosphorylation were both markedly (approximately $60-70 \%$ ) inhibited by the p38 inhibitor, SB203580. In contrast, SB203580 could only inhibit IFN- $\gamma$-induced STAT1 Ser727 phosphorylation but not STAT1 Tyr701 phosphorylation (Figure $5 \mathrm{~b}$ ). These findings indicate that $\mathrm{CnB}$-induced STAT1 Ser727 and Tyr701 phosphorylation are both mediated by $\mathrm{p} 38$ but IFN- $\gamma$-mediated signaling through STAT1 require additional regulatory components.

We have demonstrated that integrin $a \mathrm{M}$ is the specific receptor for $\mathrm{CnB}$ on macrophages. ${ }^{18}$ We therefore examined whether $\mathrm{CnB}$-induced $\mathrm{p} 38$ phosphorylation was dependent on this receptor. Antibody blocking experiments showed that CnB-induced p38 phosphorylation was markedly inhibited by preincubation with an integrin aM-blocking antibody but only 
slightly affected by TLR4-blocking antibody. Combined preincubation with integrin $a \mathrm{M}$ and TLR4 antibodies did not significantly increase the inhibition (Figure 5c). Similarly, knockdown of siRNA knockdown of integrin aM dramatically inhibited CnB-induced p38 phosphorylation (Figure 5d). Consistent with these results, integrin $a \mathrm{M}$ knockdown also a

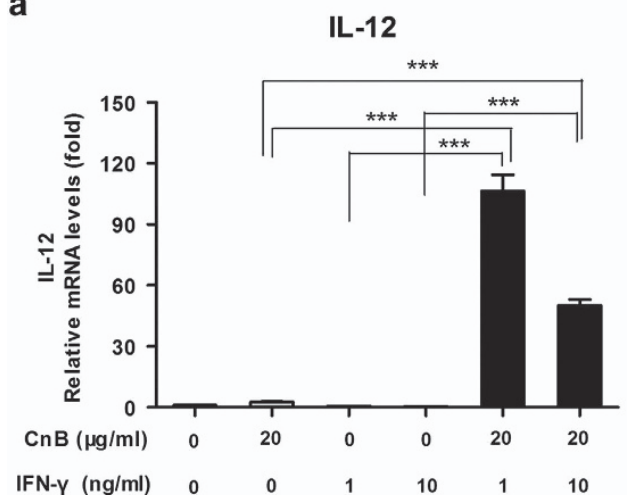

c

ARG1

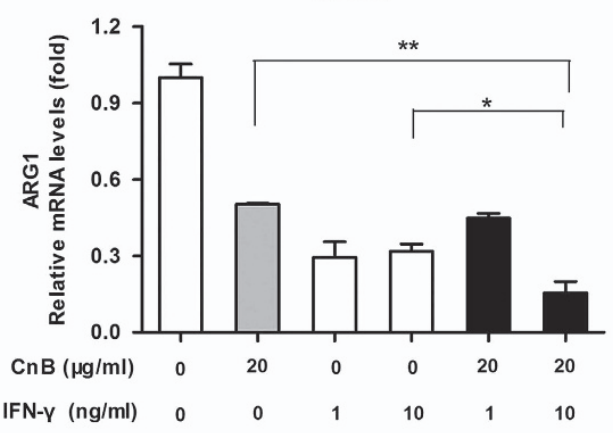

e

TRAIL

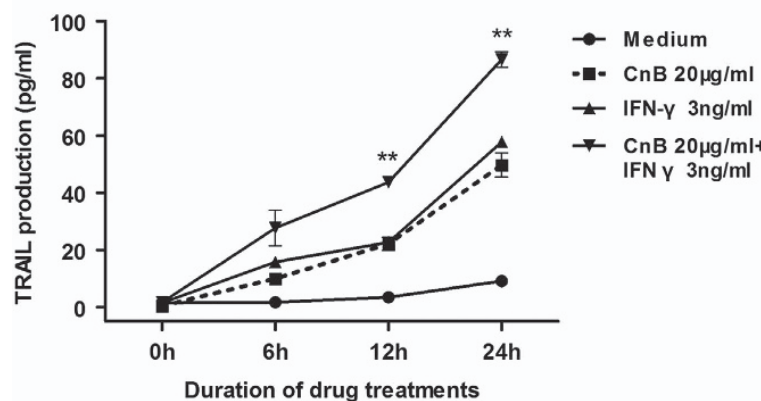

g

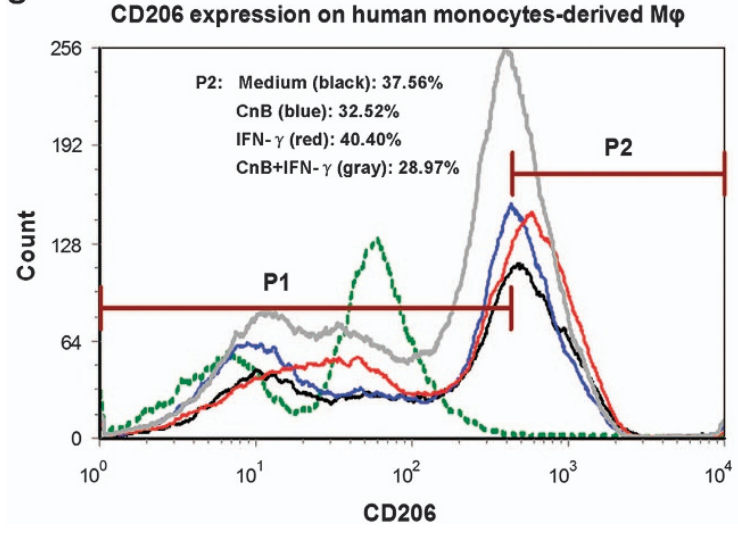

b



d

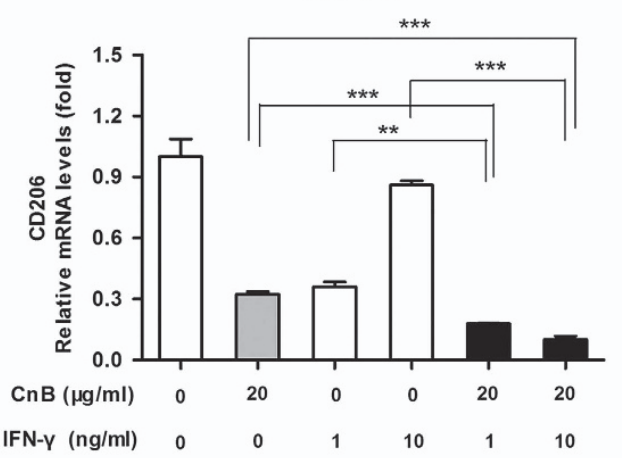

f

IL-12

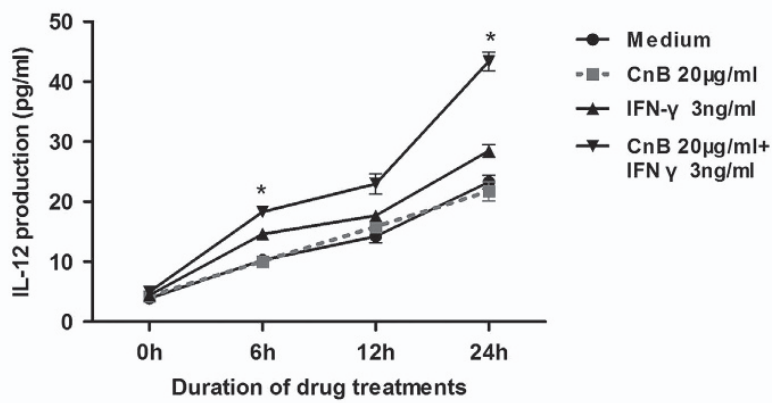


markedly attenuated CnB-induced STAT1 Ser727 and Tyr701 phosphorylation. As a control, IFN- $\gamma$-induced STAT1 Ser727 and Tyr701 phosphorylation was unaffected by integrin $a \mathrm{M}$ knockdown (Figure 5e). Collectively, these observations show that $\mathrm{CnB}$-induced STAT1 phosphorylation is dependent on integrin $a \mathrm{M}-\mathrm{p} 38$ signaling.

CnB synergizes with IFN- $\gamma$ to increase tumor-eradicating activity in vivo. Our data suggest that $\mathrm{CnB}$ primes IFN- $\gamma$ signaling through enhancing STAT1 signaling in both mouse and human cell lines. To address whether this synergy can be utilized to enhance the macrophage antitumor activity in vivo, we used a melanoma tumor model as well as a melanoma lung metastasis model. In the primary melanoma tumor model, successive treatment with $\mathrm{CnB}$ or IFN $-\gamma$ significantly prevented the melanoma growth. However, the combination of $\mathrm{CnB}$ with IFN- $\gamma$ showed a stronger suppressive effect on the tumor volume and weight than either monotherapy groups (Figures $6 \mathrm{a}$ and $\mathrm{b}$ ). Although the difference of tumor weight between the $\mathrm{CnB}$ with IFN- $\gamma$ group and the IFN $-\gamma$ alone group did not have a statistical significance, the average tumor

\section{a}
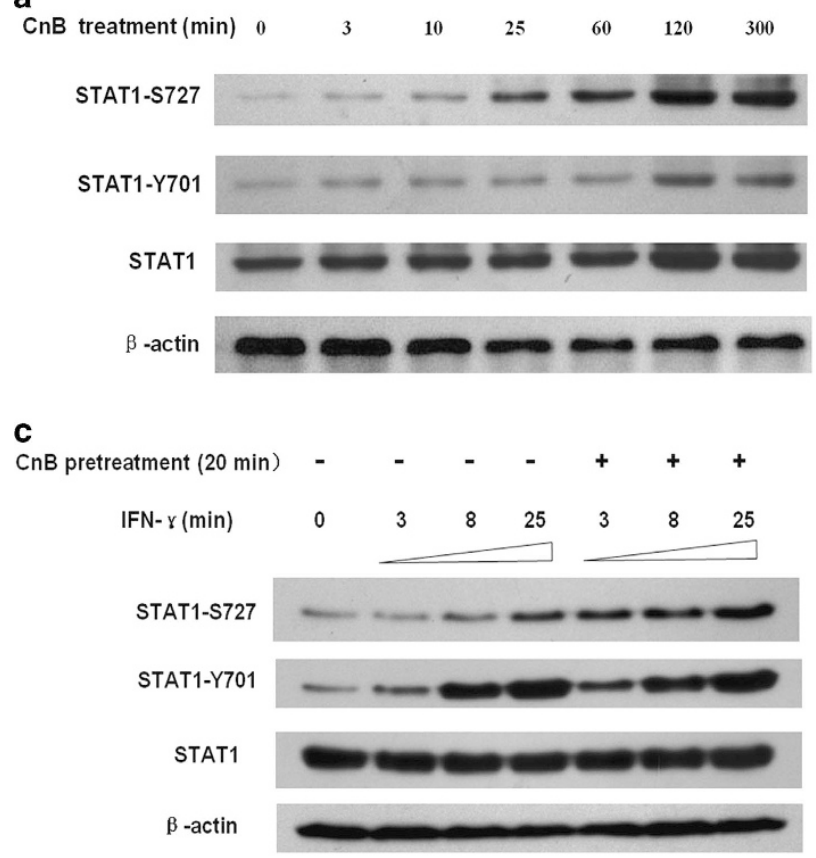

weight of the $\mathrm{CnB}$ with IFN- $\gamma$ group was lesser compared with the IFN- $\gamma$ alone group. The timing of the mice killing may affect the statistical significance among the experimental groups. Furthermore, the combination treatment induced a marked increase in active caspase-3-positive cell in isolated tumors compared with $\mathrm{CnB}$ alone or IFN- $\gamma$ alone (Figure $6 \mathrm{c}$ ). Furthermore, IL-12, CXCL10, and CD86 genes transcription in TAMs from mice of the combination group was three or more folds higher than the single-drug treatment groups (Figure 6d); this implies a stronger M1-like phenotype transformation in TAMs by combination treatment. We next evaluated the cooperative effect of $\mathrm{CnB}$ and IFN- $\gamma$ in a melanoma lung metastasis model, in which mice were injected with B16-F10 cells via the tail vein to achieve metastasis, showing that drug interventions either before or after B16 cells' inoculation can attenuate tumor metastasis and progression. In the therapeutic study, CnB and IFN- $\gamma$ acted synergistically to reduce the colonization of melanoma cells to lung tissues (Figures $7 a$ and b). As shown in Figure $7 \mathrm{~b}$, the average melanoma colony numbers in the combination group had been reduced to half to that of the

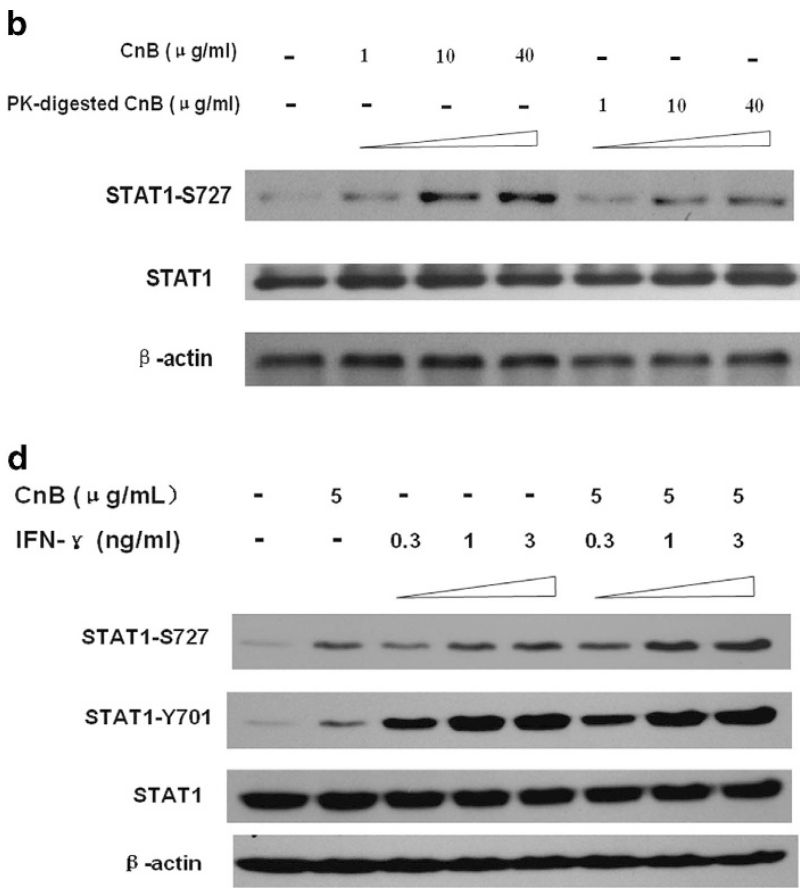

Figure $4 \mathrm{CnB}$ stimulates phosphorylation of STAT1, and combination treatment with $\mathrm{CnB}$ and IFN- $\gamma$ markedly enhances phosphorylation at Ser727 but not at Tyr701. (a) Western blotting detection of time-dependent phosphorylation of STAT1. RAW264.7 cells were treated with $20 \mu \mathrm{g} / \mathrm{ml} \mathrm{CnB}$ for 0-300 min. (b) Proteinase K-digested CnB loses the ability to induce phosphorylation of STAT1 at Ser727. Cells were incubated with $\mathrm{CnB}(1-40 \mu \mathrm{g} / \mathrm{ml})$ or proteinase K-digested $\mathrm{CnB}(1-40 \mu \mathrm{g} / \mathrm{ml})$ for $25 \mathrm{~min}$. (c) $\mathrm{CnB}$ pretreatment enhances IFN- $\gamma$-induced phosphorylation of STAT1 at Ser727 but not at Tyr701 (time course). Cells were preincubated with or without $\mathrm{CnB}(20 \mu \mathrm{g} / \mathrm{ml})$ for $20 \mathrm{~min}$, followed by incubation with IFN- $\gamma(1 \mathrm{ng} / \mathrm{ml}$ ) for 3-25 min. (d) Combined treatment with CnB and IFN- $\gamma$ synergistically promotes STAT1 phosphorylation at Ser727 but not at Tyr701 (dose course). Duration of treatments, $25 \mathrm{~min}$. Phosphorylation levels of STAT1 were quantified by densitometry and normalized to total STAT1 expression (Supplementary Figure S1)

Figure $3 \mathrm{CnB}$ synergizes with IFN- $\gamma$ to skew human monocyte-derived macrophages to an M1-like phenotype. (a-d) Quantitative PCR assay of the synergistic effect of CnB and IFN- $\gamma$ in inducing some M1 and M2 marker transcripts. a: IL-12; b: TRAIL; c: ARG1; d: CD206. (e and f) Enzyme-linked immunosorbent assay of TRAIL and IL-12 production upon $\mathrm{CnB}$ and IFN- $\gamma$ stimulation. e: TRAIL; f: IL-12. (g) Flow cytometry analysis of CD206 expression on PBMC-derived macrophages. Cell were treated with $\mathrm{CnB}(20 \mu \mathrm{g} / \mathrm{ml})$, IFN- $\gamma(3 \mathrm{ng} / \mathrm{ml})$, or $\mathrm{CnB}(20 \mu \mathrm{g} / \mathrm{ml})+\mathrm{IFN}-\gamma(3 \mathrm{ng} / \mathrm{ml})$ for $24 \mathrm{~h}$. P1, percentage of CD206-negative cells; P2, percentage of CD206-positive cells; Green: isotype control; Black: medium control; Blue: $\mathrm{CnB}$; Red: IFN- $\gamma$; Gray: $\mathrm{CnB}+\mathrm{IFN}-\gamma$. In panels $\mathbf{e}$ and $\mathbf{f}$, the $t$-tests were carried out between $\mathrm{CnB}+\mathrm{IFN}-\gamma$ treatment and IFN- $\gamma$ treatment alone. ${ }^{*} P<0.05$, ${ }^{* *} P<0.01,{ }^{* *} P<0.001$ 


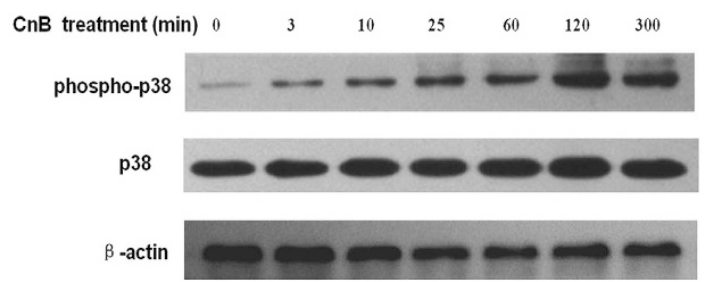

C

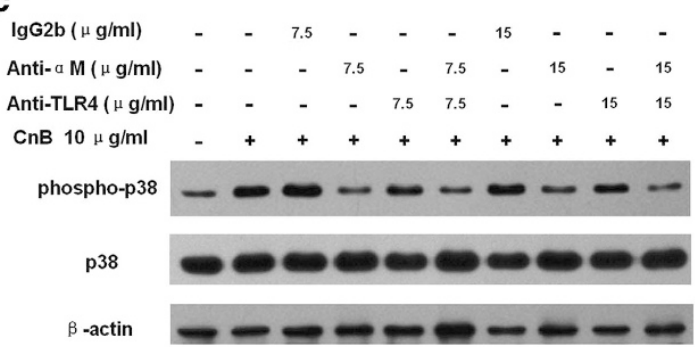

b

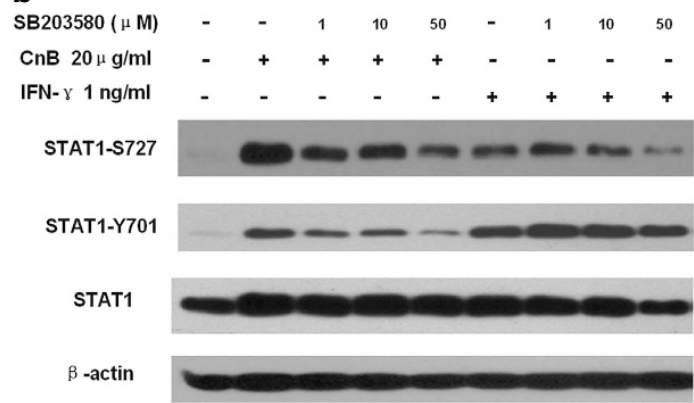

d

e

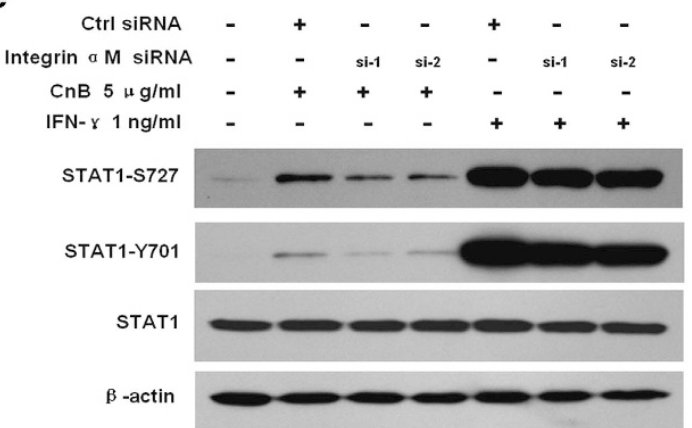

Figure $5 \mathrm{CnB}$-induced STAT1 phosphorylation is dependent on the integrin $\alpha \mathrm{M}-\mathrm{p} 38$ signaling pathway. (a) $\mathrm{CnB}$ promotes phosphorylation of p38 in a time-dependent manner. RAW264.7 macrophages were incubated with $20 \mu \mathrm{g} / \mathrm{ml} \mathrm{CnB}$ for 0-300 min, and then lysed for western blotting analysis. (b) The p38 inhibitor SB203580 markedly inhibits CnB-induced STAT1 Ser727 and Tyr701 phosphorylation. Cells were pretreated with SB203580 (1-50 $\mu \mathrm{M})$ for 30 min followed by CnB/IFN- $\gamma$ treatment for another 30 min. (c) CnB-induced p38 phosphorylation is blocked by integrin $\alpha \mathrm{M}$ antibody. Antibody concentrations, 7.5 or $15 \mu \mathrm{g} / \mathrm{ml}$; duration of antibody pretreatment, $45 \mathrm{~min}$. (d) $\mathrm{CnB}$-induced p38 phosphorylation is attenuated by integrin $\alpha \mathrm{M}$ knockdown. Forty-eight hours after siRNAs transfection, cells were incubated with $5 \mu \mathrm{g} / \mathrm{ml} \mathrm{CnB}$ for 25 min. (e) $\mathrm{CnB}$-induced STAT1 phosphorylation is attenuated by integrin $\alpha \mathrm{M}$ knockdown. Forty-eight hours after siRNAs transfection, cells were incubated with $\mathrm{CnB}(5 \mu \mathrm{g} / \mathrm{ml})$ or IFN- $\gamma(1 \mathrm{ng} / \mathrm{ml})$ for 25 min. Phosphorylation levels of STAT1 and p38 were quantified by densitometry and normalized to total STAT1 or total p38 expression, respectively (Supplementary Figure S2)

CnB or IFN- $\gamma$ group. In accordance to its desirable therapeutic efficacy, combined treatment effectively prevented mice body weight loss during tumor invasion (Figure 7c), which also implied a fact that combined treatment may not bring additional toxicity compared with single-drug treatments. In addition, two key cytokines, IL-12 and CXCL9 expression, in TAMs from mice of the combination group were many folds higher than in that of the single-drug treatment groups (Figure 7d), which was in agreement with the good performance in anatomy after combination treatment. In the prophylactic study, five successive combined treatments with $\mathrm{CnB}$ and IFN- $\gamma$ before inoculation with B16-F10 melanoma cells significantly prolonged the survival of mice compared with treatment with normal saline $(P<0.001), \mathrm{CnB}$ alone $(P<0.05)$, or IFN- $\gamma$ alone $(P<0.01)$ (Figure $7 e)$. Taken together, these data indicate that $\mathrm{CnB}$ and IFN- $\gamma$ have a marked synergistic antitumor effect in vivo.

\section{Discussion}

Immunotherapy is often recommended as an adjuvant treatment to reduce the chance of cancer recurrence or metastasis. Interferons have been used clinically for treatment of renal cell carcinoma, melanoma, hairy cell leukemia, acute myeloid leukemia, glioma, and multiple myeloma. However, IFN-induced skin, neurological, endocrine, and immune toxicities have been a factor that restrict the amounts of interferon that can be used for effective cancer therapy. ${ }^{53}$ In order to reduce the toxicity from a single-drug treatment and bypass the issue of immune tolerance, IFNs are usually combined with other immunotherapeutic drugs, chemotherapy drugs, or molecular-targeted antitumor agents. For examples, combination treatment with PEG-interferon $a-2 b$ and recombinant interleukin-2 in phase I trial resulted in a $15 \%$ partial response, a 9.0 months median progression-free survival and a 31.9 months overall survival in patients with metastatic renal 
a

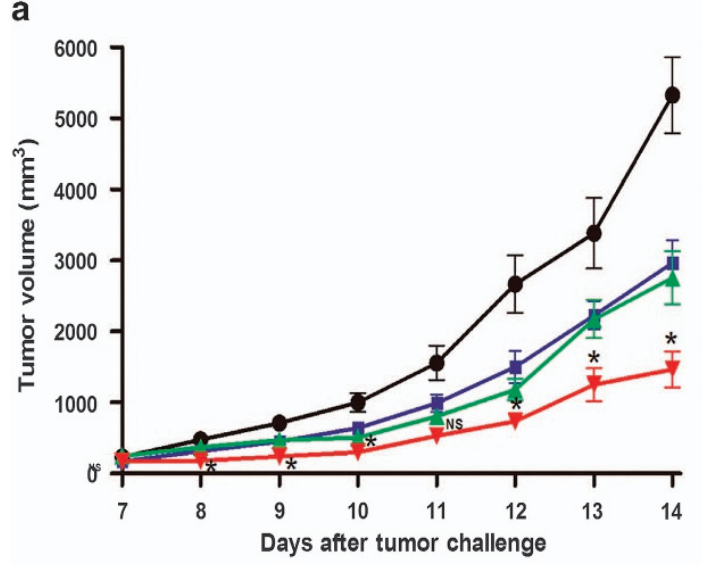

C
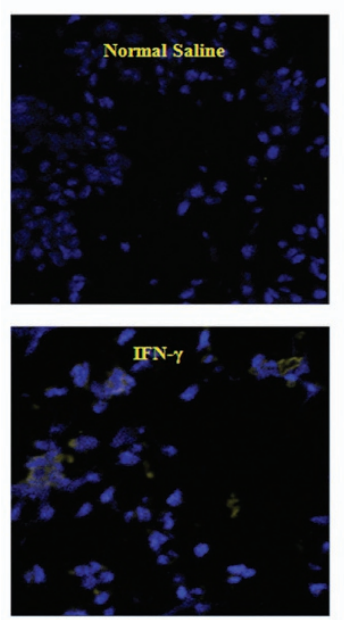
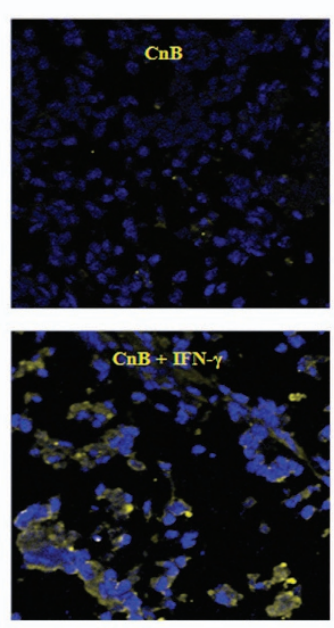

$\rightarrow \mathrm{CnB}+\mathrm{IFN}-\mathrm{y}$

$\rightarrow$ Normal saline

$\rightarrow \mathrm{CnB}$

\pm IFN-y

CnB+IFN-y vs IFN-y b

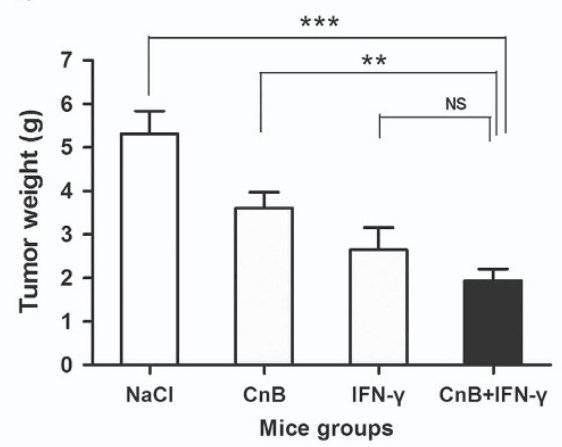

d

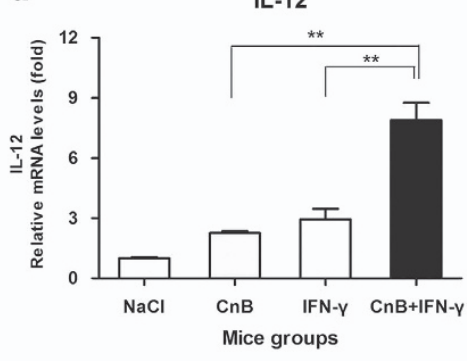

CXCL10

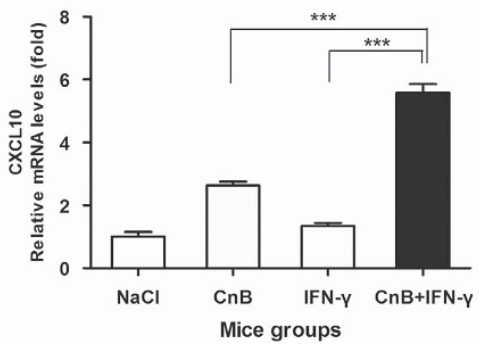

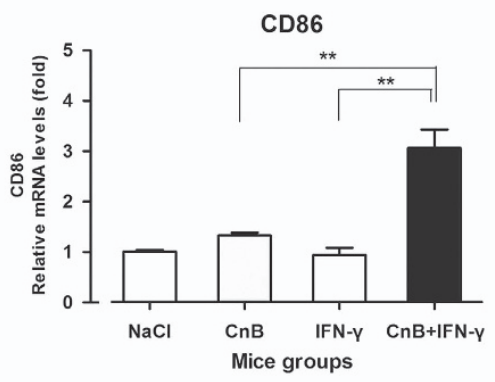

CD206

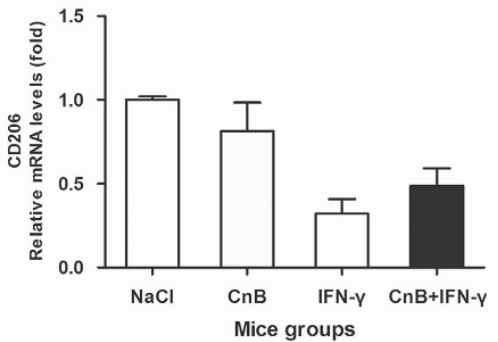

Figure 6 Synergistic antitumor effect of $\mathrm{CnB}$ and IFN- $\gamma$ in a mouse melanoma primary tumor model. (a) Tumor volume curves for different drug treatment groups. Tumor volumes were measured every day from the seventh day after tumor challenge. Nine mice for each group. (b) Average tumor weight of each group. On the second day of the last injection, mice were killed and subjected to measurement of tumor weight. (c) Immunofluorescence detection of active caspase-3 in tumor slices by confocal microscopy. Six of mice in each group were subjected to tumor slice preparation. Yellow fluorescence represents caspase-3 expression; DAPI (4,6-diamidino-2-phenylindole; blue fluorescence) was used to stain the cell nuclei. Magnification, $\times 200$. Picture above is a representative result of each group. (d) Quantitative PCR analysis of IL-12, CXCL9, CXCL10, and CD206 expression in TAMs. Data are representative result of three mice. ${ }^{*} P<0.05,{ }^{* *} P<0.01,{ }^{* *} P<0.001$, NS: no significant differences

cell carcinoma. However, high-dose therapy may lead to grade 4 neutropenia and hypoxemia. ${ }^{54}$ In a phase I/II study, IFN- $\gamma$ in combination with carboplatin and paclitaxel was applied to treat patients with advanced ovarian cancer and reached a $71 \%$ overall response rate. However, grade 3-4 neutropenia was observed in $74 \%$ of patients and other side effects, in particular peripheral neuropathies were also frequently observed. ${ }^{55}$ A phase III trial of bevacizumab plus IFN-a versus IFN- $a$ monotherapy in patients with metastatic renal cell carcinoma showed that the median overall survival time was 18.3 months for bevacizumab plus IFN- $a$ group and 17.4 months for the IFN- $a$ monotherapy group, but there was significantly more grade 3-4 hypertension, anorexia, fatigue, and proteinuria for the bevacizumab plus IFN- $a$ group. ${ }^{56}$

The examples above implicate that existing combinations between IFNs and other agents make some improvements on effectiveness compared with monotherapy, but these combination treatments are often accompanied with increased highgrade toxicity. Thus there is an urgent need for novel agents that can synergize with IFNs to achieve an antitumor activity with minimal side effects. Recombinant $\mathrm{CnB}$ protein is a newly reported candidate drug for tumor treatment by our laboratory. The advantages of $\mathrm{CnB}$ are not only in its ability to suppress tumor progression but also in its low toxicity in vitro and in vivo. Acute toxicity experiments indicated that mice can endure at least 50 -fold the physiological dose of $\mathrm{CnB} .^{20}$ Successive injections of $\mathrm{CnB}$ at therapeutic doses for several months had no detrimental effect on mouse body weight and mouse liver and spleen indexes (data not shown). Thus CnB and IFN- $\gamma$ combination treatment may provide a new way for overcoming the dosage limitation of IFN- $\gamma$ and achieve effective antitumor activity with a low toxicity. 
a
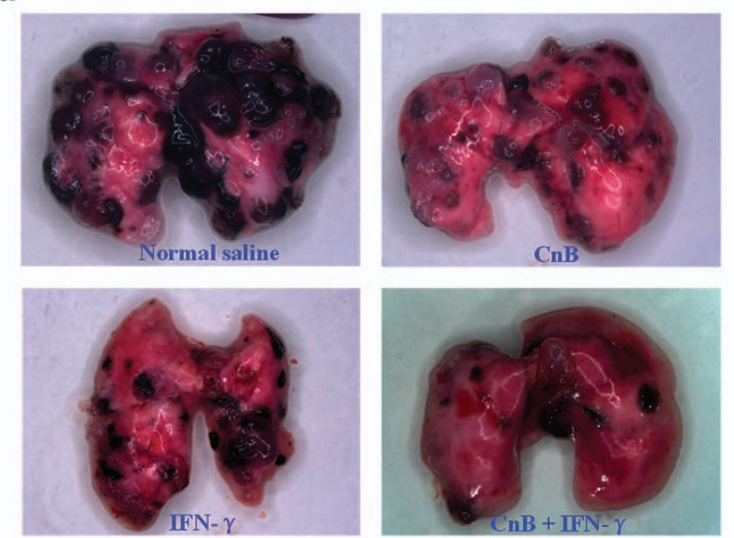

b

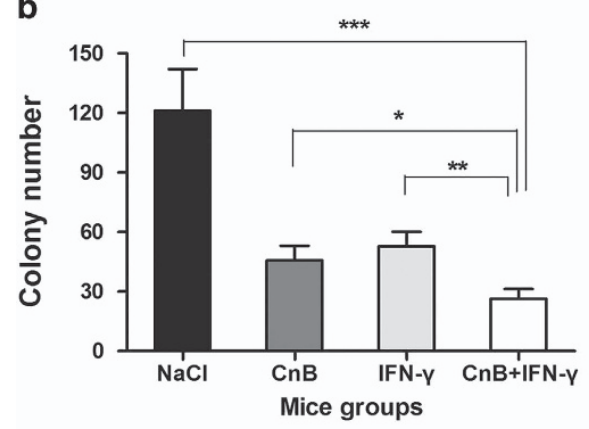

C

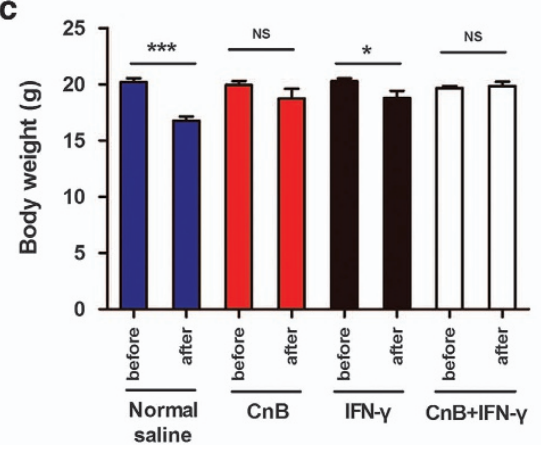

d

IL-12
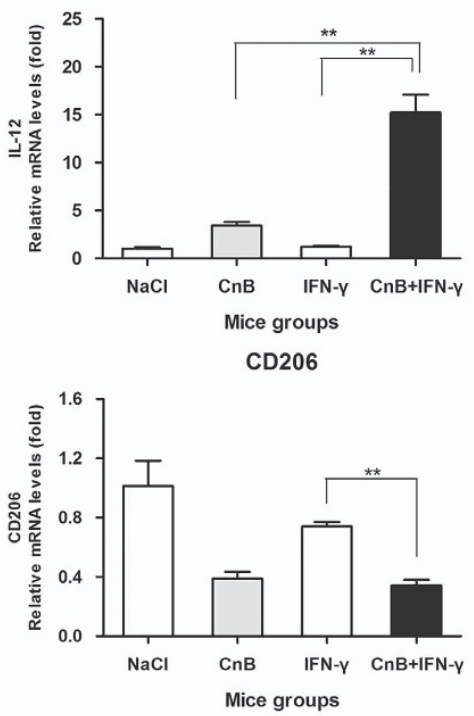

e

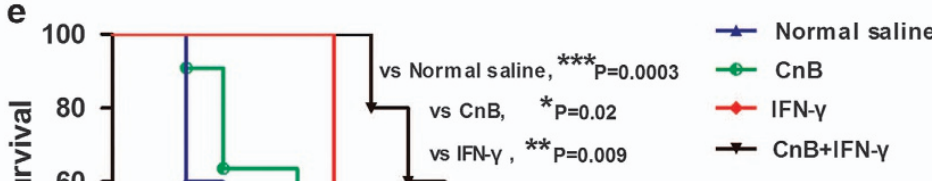

Figure 7 Synergistic tumoricidal acticity of $\mathrm{CnB}$ and IFN- $\gamma$ in a mouse melanoma lung metastasis model. (a-d) Therapeutic effect of CnB and IFN- $\gamma$. Nine mice for each group. (a) Representative isolated lungs. (b) Mean melanoma colony numbers in the lungs per mouse. (c) Body weights before and after drug treatments. (d) Quantitative PCR analysis of IL-12, CXCL9, and CD206 genes' expression in TAMs. Data are a representative result of three mice. (e) Prophylactic effect of CnB and IFN- $\gamma$. Ten mice for each group. Survival following tumor challenge was recorded. Statistical differences between treatment groups were calculated by $t$-test (Graph $\mathbf{b}-\mathbf{d}$ ) and Gehan-Breslow-Wilcoxon test (Graph e). ${ }^{*} P<0.05,{ }^{* *} P<0.01,{ }^{\star * \star} P<0.001$, NS: no significant differences

In the present study, we showed that CnB synergized with IFN- $\gamma$ to transform human monocyte-derived macrophages and mouse TAMs into an M1-like phenotype. In fact, M1 and M2 macrophages often coexist in tumor microenvironment and the changed balance of M1 and M2 macrophages can influence tumor outcome. ${ }^{44}$ Targeting the phenotype transformation has been regarded as a novel strategy for cancer treatment. Rolny et $a l^{45}$ reported that host-produced histidine-rich glycoprotein skewed TAM polarization away from the M2- to a tumorinhibiting M1-like phenotype, thus inhibiting tumor growth and metastasis as well as tumor vessel abnormalization, which was also accompanied with improved chemotherapy. In another research by Beatty et al., ${ }^{46}$ agonist CD40 mAb-activated macrophages rapidly infiltrated tumors and became tumoricidal by polarizing to a M1-differentiated phenotype and facilitated the depletion of tumor stroma, which did not necessarily depend on therapy-induced T cells. Besides CpG plus anti-interleukin10 receptor antibody, ${ }^{57}$ GTP cyclohydrolase inhibitors, ${ }^{58} \mathrm{COX}-2$ inhibitors, ${ }^{59}$ microRNA-155, ${ }^{60}$ and Notch signaling agitator ${ }^{61}$ are also reported to be involved in TAM phenotype transformation. CnB plus IFN- $\gamma$ greatly increased M1 marker (IL-12, CXCL9, CXCL10, CD86, etc.) expression in TAMs, whereas they selectively decreased some M2 markers (e.g., CD206) but not IL-10 expression. Moreover, combination of $\mathrm{CnB}$ and IFN- $\gamma$ are able to transform TAMs into an M1-like differentiation; however, this transformation might be a bit different from the classic phenotype shift, which is represented with IL-12 $2^{\text {high }}$ and IL-10 ${ }^{\text {low }}$. 
We demonstrated in this study that $\mathrm{CnB}$ stimulated both STAT1 serine and tyrosine phosphorylation, but phosphorylation of the former was much more effective than that of the latter; this was different from the strong activation of STAT1 both at Tyr701 and Ser727 by IFN- $\gamma$. Further study showed that p38 was a critical modulator in CnB-initiated STAT1 serine and tyrosine phosphorylation, which was different from the pattern seen with IFN- $\gamma$, in which IFN- $\gamma$-induced STAT1 Tyr701 phosphorylation is thought to be mediated by Jak2, but IFN$\gamma$-induced Ser727 phosphorylation is thought to be mediated by $\mathrm{p} 38$ MAPK or PKC- $\delta .^{30-32}$ Our data also supported that integrin $a \mathrm{M}$, a newly reported receptor for $\mathrm{CnB},{ }^{18}$ is required for CnB-induced p38 activation and the subsequent STAT1 activation, consistent with an earlier report that engagement of $\beta 2$-integrins can lead to p38 activation. ${ }^{62}$ To our knowledge, this is the first evidence that STAT1 phosphorylation can be mediated by integrin $a \mathrm{M}$. To summarize, $\mathrm{CnB}$ and IFN- $\gamma$ share different receptors, use different modulators, and represent different activation patterns, but they finally converge into a common key factor STAT1 and achieve a maximum activation, which leads to a rapid and intense amplification of IFN- $\gamma$ signaling. Based on our findings and previous studies by other groups, we also proposed a model to summarize the basis of the synergism of $\mathrm{CnB}$ and IFN- $\gamma$ (Figure 8).

The implications of the synergistic effect of $\mathrm{CnB}$ and IFN- $\gamma$ are not limited to the area of pharmacology; this interaction may also have potential physiological importance. Because there is a high concentration of $\mathrm{Cn}$ in blood, amniotic fluid, and cytosol of cells, ${ }^{63}$ this could permit $\mathrm{CnB}$ to interact with monocyte-macrophages in vivo. As $\mathrm{CnB}$ is constitutively expressed in blood, and IFN- $\gamma$ is stimulus dependent, we speculate that serum $\mathrm{CnB}$ may synergize with IFN- $\gamma$ when hosts are invaded by microorganisms (i.e., viruses and bacteria) or malignant tumors, conditions in which IFN- $\gamma$ levels would increase rapidly. This cooperation may rapidly induce extensive production of M1 cytokines that orchestrate a complex response to these various situations. The cooperation may actually have evolved into an immune surveillance mechanism that permits the host to respond more effectively and rapidly to internal and external dangers. This hypothesis should be further explored by neutralizing serum CnB with specific monoclonal antibodies.

\section{Materials and Methods}

Materials. Recombinant human $\mathrm{CnB}$ protein was prepared in our laboratory (The amino-acid sequences of human, mouse, and rat $\mathrm{CnB}$ protein are identical.). Endotoxin was removed with Cellufine ETclean $S$ endotoxin-removing beads (Chisso Corporation, Tokyo, Japan). The CnB was $>98 \%$ pure, and LPS contamination was $<4 \mathrm{EU} / \mathrm{mg}$. Proteinase $\mathrm{K}$ was from Roche Diagnostics (Indianapolis, IN, USA) and recombinant murine IFN- $\gamma$ from Canspec Scientific Instruments Corporation (Shanghai, China). Phospho-STAT1 Ser727, phosphoSTAT1 Tyr701, STAT1, phospho-p38, p38 antibodies, p38 inhibitor SB203580, recombinant human M-CSF, and recombinant human IFN- $\gamma$ were from Cell Signaling Technology (Beverly, MA, USA). Antiactive caspase 3 antibody and Alexa Fluor 555-conjugated secondary antibody were from Abcam (Cambridge, UK). Alexa Fluor 488-conjugated F4/80 antibody and Alexa Fluor 488-conjugated rat IgG2b isotype control were from $\mathrm{AbD}$ serotec (Oxford, UK). Integrin $\alpha \mathrm{M}$-blocking antibody, TLR4-blocking antibody, and the rat IgG2b isotype control (functional grade purified) were purchased from eBioscience (San Diego, CA, USA). PElabeled CD206 antibody, PE-labeled CD86 antibody, and related isotype antibodies were from BD PharMingen (San Diego, CA, USA). ELISA kits for TRAIL, IL-12, and CXCL9 were from R\&D Systems (Minneapolis, MN, USA) and Uscn Life Science



Figure 8 Diagram illustrating the mechanism of synergism between $\mathrm{CnB}$ and IFN- $\gamma$. CnB binds to an important macrophage membrane receptor integrin $\alpha \mathrm{M}$ and activate p38 MAPK. Activated p38 promotes strong phosphorylation of STAT1 at Ser727 and weak phosphorylation at Tyr701. At the same time, IFN- $\gamma$ binds to IFN- $\gamma$ receptors (IFNGR) and strongly induces STAT1 Ser727 phosphorylation by p38 (or PKC- $\delta$ ) and STAT1 Tyr701 phosphorylation by Jak2. Combination treatment with $\mathrm{CnB}$ and IFN- $\gamma$ greatly enhances STAT1 serine and tyrosine phosphorylation and activates STAT1 maximally. The immense activation of STAT1 causes a sudden burst of TRAIL and other antitumor M1 cytokines directly or via the transcriptional factors IRF-1 and IRF-9 and finally render macrophages re-educated, possessing more ability to eradicate tumor. '+++' represents strong activation and '+' represents weak activation

Inc. (Wuhan, China). Integrin $\alpha \mathrm{M}$ siRNA was purchased from Ribobio Co., Ltd (Guangzhou, China), and the Annexin V/PI apoptosis detection kit was from Bender Med Systems (Vienna, Austria). Collagenase type I was from Invitrogen (Carlsbad, CA, USA). Ficoll was purchased from Amersham Biosciences (Uppsala, Sweden).

Animals. C57BL/6 mice, 6-8 week of age, were purchased from Vital River Laboratories (Beijing, China). All animals were housed in microisolator cages, with autoclaved food and bedding to minimize exposure to viral and microbial pathogens, and all procedures were approved by the Institutional Animal Care and Use Committee.

TAM purification. TAM purification procedure was derived and improved from Sierra et al. ${ }^{64}$ In brief, B16 melanoma tumors grown in C57BL/6 mice were surgically removed, minced, and left to disaggregate in $0.1 \%$ collagenase I-RPMI- 1640 solution with constant stirring at $37^{\circ} \mathrm{C}$ for $60 \mathrm{~min}$. The suspension was filtered through a 200mesh sieve to obtain single-cell suspension followed by treatment with red blood cell lysis buffer for $5 \mathrm{~min}$. Cells were centrifuged and washed twice with serum-free medium and left to adhere in serum-free RPMI 1640 for $30 \mathrm{~min}$. Nonadherent cells were washed away. More than $85 \%$ of the remaining adherent cells were TAMs, as assessed by macrophage-specific marker F4/80 using flow cytometry.

Immunofluorescence. Immunofluorescent analyses were performed according to standard techniques. In brief, tumors were fixed in 4\% formaldehyde in PBS and paraffin embedded. A 4- $\mu \mathrm{m}$ thickness was cut from each paraffin block. After dewaxing and rehydration, the sections were microwaved for antigen retrieval in $10 \mathrm{mM}$ citrate buffer for $10 \mathrm{~min}$ and then allowed to cool for $1 \mathrm{~h}$ at room temperature. Sections were blocked with $5 \%$ bovine serum for $20 \mathrm{~min}$, followed by incubation with primary antibody (diluted 1:200) for $90 \mathrm{~min}$, and then with secondary conjugated antibodies (diluted $1: 400$ ) for $20 \mathrm{~min}$. Pictures were taken with a ZEISS LSM 700 microscope (Carl Zeiss, Jena, Germany). 
RNA extraction and real-time PCR. Total RNA was extracted from macrophages using an AxyPrep Multisource Total RNA Miniprep Kit (Axygen, Union City, CA, USA). Reverse transcription was performed with a PrimeScript 1st Strand cDNA Synthesis Kit (Takara, Kyoto, Japan). Real-time PCR primers were designed with the Primer 5.0 software (Premier Biosoft International, Palo Alto, CA, USA), and the sequences were as follows: mouse TRAIL forward 5 '-GCCACAGACACTTCGGTGTT $-3^{\prime}$, reverse 5'-TGATCTCATTITGCGGAAAGAA-3'; mouse CXCL9 forward 5'-TCCTT TTGGGCATCATCTTCC-3', reverse 5'-TTTGTAGTGGATCGTGCCTCG-3'; mouse CXCL10 forward 5'-TCCTTGTCCTCCCTAGCTCA-3', reverse 5'-ATAACCCCTTGG GAAGATGG-3'; mouse iNOS forward 5'-CAGATCCCGAAACGCTTCA-3', reverse 5'-T GTTGAGGTCTAAAGGCTCCG-3'; mouse IRF-1 forward 5'-CAGAGGAAAGA GAGAAAGTCC-3', reverse 5'-CACACGGTGACAGTGCTGG-3'; mouse IRF-9 forward 5'-CAGTCTAGGCTGTGCACCTG-3', reverse 5'-TTCCTGGAGCATCAACTTCC-3'; mouse IL-12 forward 5'-GACCATCACTGTCAAAGAGTTTCTAGAT-3', reverse 5'-AGGA AAGTCTTGTITITGAAATTITITAA-3'; mouse CD206 forward 5'-GCTTCCGTCA CCCTGTATGC-3', reverse 5'-TCATCCGTGGTTCCATAGACC-3'; mouse $\beta$-actin forward 5'-AGAGGGAAATCGTGCGTGAC-3', reverse 5'-CAATAGTGATGACCTGGCCGT-3'; human IL-12 forward 5'-GCTATCTGAATGCTTCCTAA-3', reverse 5'-AGTTCTTAATC CACATCCTATC-3'; human TRAIL forward 5'-AGCCTGGAATGGATTCGTGG-3', reverse 5'-GTGGCGGTITTGTCCTTCA-3' human CD206 forward 5'-CTACTATGTC TTGGAATGATAT-3', reverse 5'-TAACTGGTGGATTGTCTT-3'; human ARG1 forward 5'-TTAGATATAATGGAAGTGAA-3', reverse 5'-GTTAAGGTAGTCAATAGG-3'; and human $\beta$-actin forward $5^{\prime}$-GTGACAGCAGTCGGTGGAG-3', reverse $5^{\prime}$-AGTGGG GTGGCTTITAGGAT-3'. PCR was performed on an Applied Biosystems 7500 Real Time PCR system using SYBR Green Master Mix reagent (Applied Biosystems, Foster City, CA, USA). Reactions were performed in triplicate or duplicate.

Western blotting analysis. Western blot analysis was performed on whole cell lysates of RAW264.7 macrophages. They were resolved by SDS-PAGE under reducing conditions and electrotransferred to a PVDF membrane (Millipore, Bedford, MA, USA). The membrane was blocked with $5 \%$ nonfat milk and incubated with primary antibody overnight at $4{ }^{\circ} \mathrm{C}$, followed by incubation with HRP-conjugated goat-anti-rabbit lgG for $1 \mathrm{~h}$ at room temperature. Protein bands were detected with SuperSignal ECL reagents (Pierce, Rockford, IL, USA) and visualized by autoradiography.

RNAi. RAW264.7 macrophages were transfected with siRNAs targeting mouse integrin $\alpha \mathrm{M}$ or control siRNA using HiPerFect Transfection Reagent (Qiagen, Valencia, CA, USA) according to the manufacturer's instructions. In brief, cells were seeded at $3 \times 10^{5}$ cells per well in 12-well plates and incubated for $6 \mathrm{~h}$ in the presence of $750 \mathrm{ng}$ siRNA complexed with $18 \mu \mathrm{l}$ HiPerFect. The transfected cells were used after $48 \mathrm{~h}$. The sequences of the siRNAs targeting integrin $\alpha \mathrm{M}$ were as follows: siRNA1: sense $5^{\prime}$-GCACUGAGAUCCUGUUUAA dTdT-3', antisense 3'-dTdT CGUGACUCUAGGACAAAUU-5'; and siRNA2: sense 5'-GGAGAAUAC UUAUGUGAAU dTdT-3', antisense 3 '-dTdT CCUCUUAUGAAUACACUUA-5'.

Flow cytometry. In the H22 cells and RAW264.7 cells co-culture experiment, apoptosis of the H22 cells was examined by Annexin V-FITC/PI staining. The H22 cells were washed twice with ice-cold PBS and stained with $10 \mu \mathrm{l}$ Annexin V and $5 \mu \mathrm{PI}$ in $200 \mu \mathrm{l}$ binding buffer for $15 \mathrm{~min}$ at room temperature. After staining, $300 \mu \mathrm{l}$ of binding buffer was added to each tube, and samples were analyzed with a FACSVantage SE (BD Biosciences, San Jose, CA, USA). Unstained cell samples and cells stained with Annexin $\mathrm{V}$ or $\mathrm{PI}$ only were prepared for fluorescence compensation. In the F4/80, CD86, and CD206 expression assay, adherent TAMs or human monocyte-derived macrophages were collected by gentle scraping using the PBS/BSA buffer and washed twice with the same buffer, and then cells were incubated with flow cytometry antibodies $(5 \mu \mathrm{g} / \mathrm{ml})$ or isotype antibody $(5 \mu \mathrm{g} / \mathrm{ml})$ on ice for 20-30 min. After staining, cells were washed twice and subjected to flow cytometry analysis.

Preparation of human monocyte-derived macrophages. Blood from healthy donors was collected in heparin-treated tubes and peripheral blood mononuclear cells (PBMCs) were isolated by standard Ficoll density-gradient centrifugation. PBMCs were plated in 12-well plates $\left(1.6 \times 10^{6}\right.$ cells/well), and after $2 \mathrm{~h}$ of incubation for adherence, the medium was replaced with RPMI-1640 containing $50 \mathrm{ng} / \mathrm{ml} \mathrm{M}$-CSF. Adhered cells were incubated at $37^{\circ} \mathrm{C}$ in $5 \% \mathrm{CO}_{2}$ for $4-5$ days to induce differentiation into macrophages, with a change of half of medium at day 3 .

\section{Murine melanoma models}

Mouse melanoma primary tumor model: C57BL/6 mice were inoculated at right armpit with $1 \times 10^{6} \mathrm{~B} 16-\mathrm{F} 10$ melanoma cell and divided into four groups (normal saline group, $\mathrm{CnB}$ group, IFN- $\gamma$ group, $\mathrm{CnB}+\mathrm{IFN}-\gamma$ group; nine mice for each group). Three days after inoculation, mice were given 10 successive injections (i.p., 1 injection/day) of normal saline, $\mathrm{CnB}(20 \mathrm{mg} / \mathrm{kg} /$ day $), \mathrm{IFN}-\gamma(50 \mu \mathrm{g} / \mathrm{kg} /$ day $)$ and $\mathrm{CnB}$ plus IFN- $\gamma$ ( $20 \mathrm{mg} \mathrm{CnB}+50 \mu \mathrm{g} \mathrm{IFN}-\gamma / \mathrm{kg} /$ day), respectively. Tumor volumes were measured every day from the seventh day after tumor challenge. On the second day of last injection, mice were killd and subjected to measurement of tumor weight; then six of mice in each group were subjected to tumor slice preparation and others were used for separating TAMs.

Mouse melanoma lung metastasis model: In a therapeutic study, C57BL/6 mice were randomly divided into four groups (nine mice for each group) and injected i.v. with $3 \times 10^{5}$ B16-F10 cells via the tail vein. From the second day following inoculation, mice were injected i.p. with normal saline, CnB $(20 \mathrm{mg} / \mathrm{kg})$, IFN- $\gamma$ $(50 \mu \mathrm{g} / \mathrm{kg})$ or $\mathrm{CnB}(20 \mathrm{mg} / \mathrm{kg})$ plus IFN- $\gamma(50 \mu \mathrm{g} / \mathrm{kg})$ every day for 18 days. On the second day after the last administration, mice were killed, and the lungs were removed for photograph, colony counting, and macrophages isolation. In a prophylactic study, C57BL/6 mice were randomly divided into four groups (10 mice for each group) and injected i.p. with normal saline, $\mathrm{CnB}(5.0 \mathrm{mg} / \mathrm{kg})$, IFN- $\gamma(50 \mu \mathrm{g} / \mathrm{kg})$ and $\mathrm{CnB}(5.0 \mathrm{mg} / \mathrm{kg})$ plus IFN- $\gamma(50 \mu \mathrm{g} / \mathrm{kg})$, respectively, every 2 days for 10 days; then the mice were injected i.v. with $3 \times 10^{5}$ B16-F10 cells in $200 \mu$ l normal saline via their tail vein. Survival following tumor challenges was recorded.

Statistical analysis. Data were expressed as means and S.E.Ms. Data were analyzed by two-tailed $t$-tests and Gehan-Breslow-Wilcoxon test (for survival curve analysis). $P<0.05$ was considered statistically significant.

\section{Conflict of Interest}

The authors declare no conflict of interest.

Acknowledgements. We thank Dimitry Ofengeim for his kind help in editing this paper. The work was supported by grants from the National Natural Science Foundation of China (Nos. 31300666 and 31270849), the National Important Novel Medicine Research Project, and the International Cooperation Project.

1. Crabtree GR. Generic signals and specific minireview outcomes: signaling through $\mathrm{Ca}^{2+}$ calcineurin, and NF-AT. Cell 1999; 96: 611-614.

2. Manalan AS, Klee CB. Activation of calcineurin by limited proteolysis. Proc Natl Acad Sci 1983; 80: 4291-4295.

3. Clipstone N, Crabtree G. Identification of calcineurin as a key signalling enzyme in T-lymphocyte activation. Nature 1992; 357: 695.

4. Malleret G, Haditsch U, Genoux D, Jones MW, Bliss TVP, Vanhoose AM et al. Inducible and reversible enhancement of learning, memory, and long-term potentiation by genetic inhibition of calcineurin. Cell 2001; 104: 675-686.

5. Jurado S, Biou V, Malenka RC. A calcineurin/AKAP complex is required for NMDA receptordependent long-term depression. Nat Neurosci 2010; 13: 1053-1055.

6. Wang HG, Pathan N, Ethell IM, Krajewski S, Yamaguchi Y, Shibasaki F et al. $\mathrm{Ca}^{2+}$-induced apoptosis through calcineurin dephosphorylation of BAD. Science 1999; 284: 339.

7. Wang JX, Jiao JQ, Li Q, Long B, Wang K, Liu JP et al. miR-499 regulates mitochondrial dynamics by targeting calcineurin and dynamin-related protein-1. Nat Med 2010; 17: 71-78.

8. Sussman MA, Lim HW, Gude N, Taigen T, Olson EN, Robbins J et al. Prevention of cardiac hypertrophy in mice by calcineurin inhibition. Science 1998; 281: 1690-1693.

9. Heineke J, Auger-Messier M, Correll RN, Xu J, Benard MJ, Yuan W et al. CIB1 is a regulator of pathological cardiac hypertrophy. Nat Med 2010; 16: 872-879.

10. Shi L, Jackstadt R, Siemens H, Li H, Kirchner T, Hermeking H. p53-Induced miR-15a/16-1 and AP4 form a double-negative feedback loop to regulate epithelial-mesenchymal transition and metastasis in colorectal cancer. Cancer Res 2014; 74: 532-542.

11. Neilson JR, Winslow MM, Hur EM, Crabtree GR. Calcineurin B1 is essential for positive but not negative selection during thymocyte development. Immunity 2004; 20: 255-266.

12. Heit JJ, Apelqvist ÅA, Gu X, Winslow MM, Neilson JR, Crabtree GR et al. Calcineurin/NFAT signalling regulates pancreatic $\beta$-cell growth and function. Nature 2006; 443: 345-349.

13. Li W, Handschumacher RE. Identification of two calcineurin B-binding proteins: tubulin and heat shock protein 60. Biochim Biophys Acta 2002; 1599: 72-81.

14. Saeki M, Irie Y, Ni L, Itsuki Y, Terao Y, Kawabata S et al. Calcineurin potentiates the activation of procaspase-3 by accelerating its proteolytic maturation. J Biol Chem 2007; 282: 11786.

15. Li N, Zhang Z, Zhang W, Wei Q. Calcineurin B subunit interacts with proteasome subunit alpha type 7 and represses hypoxia-inducible factor-1a activity via the proteasome pathway. Biochem Biophys Res Commun 2011; 405: 468-472. 
16. Li J, Guo JX, Su ZY, Hu ML, Liu W, Wei Q. Calcineurin subunit B activates dendritic cells and acts as a cancer vaccine adjuvant. Int Immunol 2011; 23: 327.

17. Hu M, Su Z, Yin Y, Li J, Wei Q. Calcineurin B subunit triggers innate immunity and acts as a novel Engerix- $B^{\circledR}$ HBV vaccine adjuvant. Vaccine 2012; 30: 4719-4727.

18. Liu L, Su Z, Xin S, Cheng J, Li J, Xu L et al. The calcineurin B subunit $(\mathrm{CnB})$ is a new ligand of integrin $\alpha \mathrm{M}$ that mediates $\mathrm{CnB}$-induced Apo2L/TRAIL expression in macrophages. $J$ Immunol 2012; 188: 238-247.

19. Su Z, Xin S, Xu L, Cheng J, Guo J, Li L et al. The calcineurin B subunit induces TNF-related apoptosis-inducing ligand (TRAIL) expression via CD11b-NF-kB pathway in RAW264. 7 macrophages. Biochem Biophys Res Commun 2012; 417: 777-783.

20. Wei Q, Lian ML, Jing FZ, Zhang N, Yan MS, Chen Y et al. Studies of calcineurin B subunit from genetic engineering for use in medicine. Drug Dev Res 2002; 56: 40-43.

21. Schoenborn JR, Wilson CB. Regulation of interferon- $\gamma$ during innate and adaptive immune responses. Adv Immunol 2007; 96: 41-101.

22. Tu SP, Quante M, Bhagat G, Takaishi S, Cui G, Yang XD et al. IFN- $\gamma$ inhibits gastric carcinogenesis by inducing epithelial cell autophagy and T-cell apoptosis. Cancer Res 2011; 71: 4247.

23. Peng W, Liu C, Xu C, Lou Y, Chen J, Yang Y et al. PD-1 blockade enhances t cell migration to tumors by elevating IFN- $\gamma$ inducible chemokines. Cancer Res 2012; 72: 5209-5218.

24. Lüth S, Schrader J, Zander S, Carambia A, Buchkremer J, Huber S et al. Chronic inflammatory IFN- $\gamma$ signaling suppresses hepatocarcinogenesis in mice by sensitizing hepatocytes for apoptosis. Cancer Res 2011; 71: 3763-3771.

25. Ngiow SF, von Scheidt B, Akiba H, Yagita H, Teng MWL, Smyth MJ. Anti-TIM3 antibody promotes T cell IFN- $\gamma$-mediated antitumor immunity and suppresses established tumors. Cancer Res 2011; 71: 3540-3551.

26. Takeda K, Nakayama M, Sakaki M, Hayakawa Y, Imawari M, Ogasawara K et al. IFN- $\gamma$ production by lung NK cells is critical for the natural resistance to pulmonary metastasis of B16 melanoma in mice. $J$ Leukoc Biol 2011; 90: 777-785.

27. Frucht DM, Fukao T, Bogdan C, Schindler $\mathrm{H}$, O'Shea JJ, Koyasu S. IFN- $\gamma$ production by antigen-presenting cells: mechanisms emerge. Trends Immunol 2001; 22: 556-560.

28. Ménard C, Blay JY, Borg C, Michiels S, Ghiringhelli F, Robert C et al. Natural killer cell IFN- $\gamma$ levels predict long-term survival with imatinib mesylate therapy in gastrointestinal stromal tumor-bearing patients. Cancer Res 2009; 69: 3563-3569.

29. Durbin JE, Hackenmiller R, Simon MC, Levy DE. Targeted disruption of the mouse Stat gene results in compromised innate immunity to viral disease. Cell 1996; 84: 443-450.

30. Goh KC, Haque SJ, Williams BRG. p38 MAP kinase is required for STAT1 serine phosphorylation and transcriptional activation induced by interferons. EMBO J 1999; 18: 5601-5608.

31. Kovarik P, Stoiber D, Eyers PA, Menghini R, Neininger A, Gaestel M et al. Stress-induced phosphorylation of STAT1 at Ser727 requires p38 mitogen-activated protein kinase whereas IFN- $\gamma$ uses a different signaling pathway. Proc Natl Acad Sci 1999; 96: 13956.

32. Deb DK, Sassano A, Lekmine F, Majchrzak B, Verma A, Kambhampati S et al. Activation of protein kinase $C \delta$ by IFN- $\gamma$. J Immunol 2003; 171: 267-273.

33. Wen Z, Zhong Z, Darnell JE. Maximal activation of transcription by Statl and Stat3 requires both tyrosine and serine phosphorylation. Cell 1995; 82: 241-250.

34. Zhang X, Blenis J, Li HC, Schindler C, Chen-Kiang S. Requirement of serine phosphorylation for formation of STAT-promoter complexes. Science 1995; 267: 1990-1994.

35. Ouchi T, Lee SW, Ouchi M, Aaronson SA, Horvath CM. Collaboration of signal transduce and activator of transcription 1 (STAT1) and BRCA1 in differential regulation of IFN- $\gamma$ target genes. Proc Natl Acad Sci 2000; 97: 5208.

36. Zhang JJ, Zhao Y, Chait BT, Lathem WW, Ritzi M, Knippers R et al. Ser727-dependent recruitment of MCM5 by Stat1 $\alpha$ in IFN- $\gamma$-induced transcriptional activation. EMBO J 1998 17: 6963-6971.

37. Gollob JA, Schnipper CP, Murphy EA, Ritz J, Frank DA. The functional synergy between $\mathrm{IL}-12$ and IL-2 involves p38 mitogen-activated protein kinase and is associated with the augmentation of STAT serine phosphorylation. J Immunol 1999; 162: 4472-4481.

38. Dalpke AH, Eckerle S, Frey M, Heeg K. Triggering of Toll-like receptors modulates IFN- $\gamma$ signaling: involvement of serine 727 STAT1 phosphorylation and suppressors of cytokine signaling. Eur J Immunol 2003; 33: 1776-1787.

39. Kovarik P, Stoiber D, Novy M, Decker T. Stat1 combines signals derived from IFN- $\gamma$ and LPS receptors during macrophage activation. EMBO J 1998; 17: 3660-3668.

40. Mantovani A, Sica A. Macrophages, innate immunity and cancer: balance, tolerance, and diversity. Curr Opin Immunol 2010; 22: 231-237.

41. Qian BZ, Pollard JW. Macrophage diversity enhances tumor progression and metastasis Cell 2010; 141: 39-51.

42. Mantovani A, Sozzani S, Locati M, Allavena P, Sica A. Macrophage polarization: tumorassociated macrophages as a paradigm for polarized M2 mononuclear phagocytes. Trends Immunol 2002; 23: 549-555.

43. Shaykhiev R, Krause A, Salit J, Strulovici-Barel Y, Harvey B-G, O'Connor TP et al. Smoking dependent reprogramming of alveolar macrophage polarization: implication for pathogenesis of chronic obstructive pulmonary disease. J Immunol 2009; 183: 2867-2883.

44. Movahedi K, Laoui D, Gysemans C, Baeten M, Stangé G, Van den Bossche J et al. Different tumor microenvironments contain functionally distinct subsets of macrophages derived from Ly6C (high) monocytes. Cancer Res 2010; 70: 5728-5739.
45. Rolny C, Mazzone M, Tuques S, Laoui D, Johansson I, Coulon C et al. HRG inhibits tumor growth and metastasis by inducing macrophage polarization and vessel normalization through downregulation of PIGF. Cancer Cell 2011; 19: 31-44.

46. Beatty GL, Chiorean EG, Fishman MP, Saboury B, Teitelbaum UR, Sun W et al. CD40 agonists alter tumor stroma and show efficacy against pancreatic carcinoma in mice and humans. Science 2011; 331: 1612-1616.

47. Kota RS, Rutledge JC, Gohil K, Kumar A, Enelow RI, Ramana CV. Regulation of gene expression in RAW 264.7 macrophage cell line by interferon- $\gamma$. Biochem Biophys Res Commun 2006; 342: 1137-1146.

48. Majumder S, Zhou LZH, Chaturvedi P, Babcock G, Aras S, Ransohoff RM. p48/STAT-1 $\alpha$ containing complexes play a predominant role in induction of IFN- $\gamma$-inducible protein, $10 \mathrm{kDa}$ (IP-10) by IFN- $\gamma$ alone or in synergy with TNF- $\alpha$. J Immunol 1998; 161: 4736

49. Clarke N, Jimenez-Lara AM, Voltz E, Gronemeyer H. Tumor suppressor IRF-1 mediates retinoid and interferon anticancer signaling to death ligand TRAIL. EMBO J 2004; 23: 3051-3060.

50. Saura M, Zaragoza C, Bao C, McMillan A, Lowenstein CJ. Interaction of interferon regulatory factor-1 and nuclear factor kappa B during activation of inducible nitric oxide synthase transcription1. J Mol Biol 1999; 289: 459-471.

51. Schroder K, Hertzog PJ, Ravasi T, Hume DA. Interferon- $\gamma$ : an overview of signals, mechanisms and functions. J Leukoc Biol 2004; 75: 163-189.

52. Kovarik $P$, Stoiber $D$, Novy M, Decker T. Stat 1 combines signals derived from IFN- $\gamma$ and LPS receptors during macrophage activation. EMBO J 1998; 17: 3660-3668.

53. Gutterman JU. Cytokine therapeutics: lessons from interferon alpha. Proc Natl Acad Sci USA 1994; $91: 1198$

54. George S, Hutson TE, Mekhail T, Wood L, Finke J, Elson P et al. Phase I trial of PEGinterferon and recombinant IL-2 in patients with metastatic renal cell carcinoma. Cancer Chemother Pharmacol 2008; 62: 347-354.

55. Marth C, Windbichler G, Hausmaninger H, Petru E, Estermann K, Pelzer A et al. Interferongamma in combination with carboplatin and paclitaxel as a safe and effective first-line treatment option for advanced ovarian cancer: results of a phase I/II study. Int J Gynecol Cancer 2006; 16: 1522-1528.

56. Rini BI, Halabi S, Rosenberg JE, Stadler WM, Vaena DA, Archer L et al. Phase III trial of bevacizumab plus interferon alfa versus interferon alfa monotherapy in patients with metastatic renal cell carcinoma: final results of CALGB 90206. J Clin Oncol 2010; 28. 2137-2143.

57. Guiducci C, Vicari AP, Sangaletti S, Trinchieri G, Colombo MP. Redirecting in vivo elicited tumor infiltrating macrophages and dendritic cells towards tumor rejection. Cancer Res 2005; 65: 3437-3446

58. Pickert G, Lim HY, Weigert A, Häussler A, Myrczek T, Waldner M et al. Inhibition of GTP cyclohydrolase attenuates tumor growth by reducing angiogenesis and M2-like polarization of tumor associated macrophages. Int J Cancer 2012; 132: 591-604.

59. Nakanishi Y, Nakatsuji M, Seno H, Ishizu S, Akitake-Kawano R, Kanda K et al. COX-2 inhibition alters the phenotype of tumor-associated macrophages from M2 to M1 in ApcMin/+ mouse polyps. Carcinogenesis 2011; 32: 1333-1339.

60. Cai X, Yin Y, Li N, Zhu D, Zhang J, Zhang C-Y et al. Re-polarization of tumor-associated macrophages to pro-inflammatory M1 macrophages by microRNA-155. J Mol Cell Biol 2012; 4: 341-343.

61. Wang Y-C, He F, Feng F, Liu X-W, Dong G-Y, Qin H-Y et al. Notch signaling determines the $\mathrm{M} 1$ versus $\mathrm{M} 2$ polarization of macrophages in antitumor immune responses. Cancer Res 2010; 70: 4840-4849.

62. Scott MJ, Billiar TR. $\beta 2$-integrin-induced p38 MAPK activation is a key mediator in the CD14/ TLR4/MD2-dependent uptake of lipopolysaccharide by hepatocytes. J Biol Chem 2008; 283 : 29433-29446.

63. Padma S, Subramanyam C. Extracellular calcineurin: identification and quantitation in serum and amniotic fluid. Clin Biochem 1999; 32: 491-494.

64. Sierra JR, Corso S, Caione L, Cepero V, Conrotto P, Cignetti A et al. Tumor angiogenesis and progression are enhanced by Sema4D produced by tumor-associated macrophages. J Exp Med 2008; 205: 1673-1685.



Cell Death and Disease is an open-access journal published by Nature Publishing Group. This work is licensed under a Creative Commons Attribution 4.0 International License. The images or other third party material in this article are included in the article's Creative Commons license, unless indicated otherwise in the credit line; if the material is not included under the Creative Commons license, users will need to obtain permission from the license holder to reproduce the material. To view a copy of this license, visit http://creativecommons.org/licenses/by/4.0/ 